\title{
DISTRIBUIÇÃO GEOGRÃFICA DOS PRINCIPAIS VETORES DE ENDEMIAS NO ESTADO DO CEARÁ. - I - TRIATOMINNEOS
}

\author{
J.E. Alencar *, A.R. Santos**, O.F. Bezerra*** \\ e T.M. Saraiva* *
}

São apresentadas as principais informações de ordem geográfica do Estado, que é dividido em 23 micro-regiões e 141 municipios. Desses, em 129 foram encontrados triatomíneos, de acordo com informações obtidas em diversos organismos de pesquisa, de 1957 a 1974. A espécie principal no Estado é o Triatoma brasiliensis, semi-doméstico. encontrado nas casas de $91,5 \%$ dos municípios (129), suas taxas de infecção variam de 1,0 a 40,4\% (média de 8,2\%), o P. megistus é a terceira espécie e é encontrado em $61,7 \%$ dos municipios (87), com uma taxa de infecção muito variável, com média de 3,9\% e máxima de 25,9\%. Em áreas restritas como a do Cariri essa taxa subirá para 24,5\%. A segunda espécie, menos doméstica que as duas primeiras é o T. pseudomaculata, encontrado em $68,8 \%$ dos municípios e taxas de infecção variando de $0,3 \%$ a $7,1 \%$ e uma média de $4,2 \%$. A quarta espécie é o Rhodnius nasutus, encontrado em $17,7 \%$ dos municípios e infectado em 1,0\%. Penetrando na casa (não foram encontradas ninfas) há uma quinta espécie, o Panstrongylus lutzi capturado em algumas casas de 26 municipios (18,4\%) e com elevadas taxas de infecção: $17,9 \%$.

Com taxas globais de triatomíneos infectados por T. cruzi acima de $10 \%$ estão 12 municipios, dos quais mais da metade constitui as 4 micro-regiões centrais do Estado: Sertão de Quixeramobim, Sertão de Senador Pompeu, Sertão dos Inhamuns e Médio Jaguaribe.

\section{IDENTIFICAÇÃO DO ESTADO DO CEARÁ ${ }^{8}$}

O Estado do Ceará ocupa área de $148.016 \mathrm{~km}^{2}$, e se estende ao longo de $538 \mathrm{~km}$. de costa. Abrangendo áreas de relevos, o Ceará apresenta, na sua maior extensão, terrenos topograficamente deprimidos e semi-áridos, que se estendem do interior ao litoral. Sob esse aspecto, difere de outros Estados nordestinos, onde dominam as três paisagens diferenciadas de Mata, Agreste e Sertão.

Embora a semi-aridez constitua traço marcante do espaço físico cearense, os contrastes topográficos existentes dão origem a condições geográficas particulares. Serras, sertões, chapa das e várzeas de aluvião compõem os quadros geo-econômicos regionais. Os sertões constiturdos por depressões de fracas altitudes, com precipitações escassas e concentradas, solos rasos e caatingas que, desde o passado, foram ocupadas pelo gado. Contrastando com a topografia rebaixada dos sertões erguem-se as serras, serrotes e chapadas como áreas verdejantes, de precipitações pluviométricas mais abundantes e mais distribuídas, com vegetação floral e solos tropicais. De economia complementar, serras e sertões compõem os principais quadros do espaço geo-econômico cearense, completados

\footnotetext{
* Professor de Parasitologia. Departamento de Patologia e Medicina Legal do Centro de Ciências da Saúde da Universidade Federal do Ceará.

* * Chefe do Setor Ceará da SUCAM. Ministério da Saúde.

* * Zoblogo-Pesquisador da SUCAM. Ministério da Saúde. Recebido para publicação em 23-9-1976.
} 
pelos vales de aluvião e água subterrânea, e por extenso litoral de tabuleiros.

O Ceará possui uma população desigualmente distribuída, rarefeita nos sertões e adensada nas serras. Os sertões apresentam, além do gado, o cultivo do algodão, principal produto agrícola do Estado. As serras têm produção diversificada, constituindo a cultura da cana-de-açúcar importante elemento da paisagem.

\section{Estrutura Espacial}

Os quadros regionais - sertões, serras, brejos, vales e litoral - apresentam aspectos diversos quanto à distribuição da população, à utilização da terra, regime fundiário e formas de implantação da vida urbana.

Os sertões constituem a mais extensa das regiões cearenses, de fracas densidades demográficas, de vida econômica baseada na pecuária, na lavoura do algodão e na policultura de subsistência.

Marcados pela semi-aridez e por secas periódicas que desorganizam a vida econômica do Estado, os sertões foram objeto de uma política de intervenção que buscava atenuar os efeitos das crises climáticas. Diversos reservatórios d'água foram construídos, visando a atender ao problema da escassez de água, permitindo os pequenos cultivos de vazante.

Nas serras e brejos, além dos produtos de subsistência, a cana-de-açúcar, o café e a banana constituem as bases da vida econômica. Menos sujeitos às secas, as serras e brejos concentram populações e lavouras em pequenas propriedades, algumas autênticos minifúndios. Daí resul. tam pressões demográficas e maior mobilidade de população que nas próprias áreas sertanejas. Os centros urbanos constituem geralmente pontos de convergência da produção regional, e primeira etapa no movimento migratório para Fortaleza, - grande foco de atração de populações do interior.

De maneira geral, a estrutura do espaço cearense guarda seus aspectos tradicionais, embora estímulos provocados pelos mercados consumidores tenham levado ao aumento de produção, com a expansão das lavouras.

Entre os programas em execução, destacamse os de irrigação, que visam a utilizar os recursos d'água existentes, tanto os subterrâneos como os da açudagem já instalada.

No esforço de desenvolvimento do Ceará atuam a SUDENE e o Governo do Estado, cabendo ainda ressaltar o papel de duas Universidades na criação de uma mentalidade renova- dora, e na formação dos quadros técnicos e culturais indispensáveis à execução dos programas.

\section{Micro-Regiões Homogêneas}

$\mathrm{O}$ território cearense compreende vinte e três Micro-Regiões Homogêneas (Mapa 1):

a) - Micro-Região de Fortaleza (59) - Tem como principal aspecto a cidade de Fortaleza, que é o mais importante centro demográfico, econômico e cultural do Ceará. Convergindo para a cidade e irradiando para o interior, as vias de circulação garantem a Fortaleza o papel de metrópole nordestina e do meio-norte; localizada sobre planície dunar e sobre tabuleiros, a cidade é emoldurada no interior pelos relevos das serras de Maranguape e Pacatuba, cujas populações estão diretamente vinculadas à Capital. Sítios e granjas, com cultivo de produtos hortícolas, cereais e algodão são encontrados na região, acrescentando-se ainda a cana-de-açúcar no vale do Maranguape; a presença da carnaúba completa a paisagem. No censo de 1970, esta foi a Micro-Região que apresentou a mais alta densidade demográfica no Estado - 298,03 habitantes por $\mathrm{Km}^{2}$.

b) - Micro-Região do Litoral de Pacajús (60) - Os tabuleiros ao Sul de Fortaleza apresentam aspecto característico, com granjas e cajueirais plantados, havendo industrialização de frutas em Pacajús.

c) - Micro-Região da Serra de Baturité (65) - Constitui importante zona agrícola, situada em área próxima e diretamente vinculada a Fortaleza, por rodovia asfaltada. Na serra aparecem as tradicionais lavouras da cana-de-açúcar para a produção de rapadura e aguardente, e os cafezais. A fruticultura (sobretudo da banana) e a horticultura constituem setores que vêm sendo estimulados pelo mercado consumidor da Capital.

d) - Micro-Região de Sobral (63) - A cidade de Sobral constitui o principal núcleo urbano do Vale do Aracaú. Sua posição garantiu-Ihe o desenvolvimento como centro de coleta e comercialização da produção do algodão, da oiticica, da cera de carnaúba e dos couros e peles dos sertões, que se estendem do Aracati-Açu à Serra da Ibiapaba. A região apresentou quadros naturais variados: $O$ Vale do Acaraú, os pés de serra e as serras da Meruoca - Rosário e parte do pé de serra da Ibiapaba. A exploração agrícola é diversificada, abrangendo o algodão, o milho, o feijão e a mandioca nas serras e pés de serra, e a pecuária 
nas áreas mais secas. Na várzea do Acaraú desenvolvem-se o extrativismo da oiticica e o da carnaúba, cuja palha constitui objeto de artesanato que ocupa considerável contingente de populações.

e) - Micro-Região dos Sertões de Canindé (64) - De configuração alongada de leste para oeste, a região apresenta, em Canindé, Caridade e Paramoti, predomínio da vida agrícola, como o algodão e culturas de subsistência, enquanto em Santa Quitéria domina a atividade pastoril.

f) - Micro-Região dos Sertões de Crateús (67) - Os sertões de Crateús ocupam as cabeceiras e a bacia do alto curso do rio Poti. A atividade pastoril é praticada no sertão e a agricultura do feijão, milho e mamona nos relevos mais pronunciados, pés de serra e divisores de água.

g) - Micro-Região dos Sertões de Quixeramobim (68) - É formada por vastas depressões sertanejas, pontuadas pelos relevos rochosos que se erguem meio ao aplanamento geral. Tradicionalmente pastoris, os sertões de Quixadá e Quixeramobim têm na pecuária e no cultivo do algodão arbóreo as principais atividades.

h) - Micro-Região dos Sertões de Senador Pompeu (69) - Como a Micro-Região precedente, a de Senador Pompeu é igualmente formada por vastos aplanamentos em caatinga, onde o gado se instalou, e pés de serra e serras secas, onde a vida agrícola se desenvolve em torno do algodão arbóreo, milho e algodão herbáceo. Na serra da Pedra Branca cultivam-se arroz e cana-de-açúcar.

i) - Micro-Região do Médio Jaguaribe (70) - Constitui área pastoril por excelência, de pecuária leiteira, com produção de queijos, e pecuária de corte. Na produção agrícola destacam-se a cultura do algodão herbáceo, nos baixios, e a do algodão arbóreo nos trechos sertanejos. Os centros urbanos da região são pouco expressivos.

j) - Micro-Região do Sertão dos Inhamuns (72) - O povoamento da região dos Inhamuns se fez com fazendas de gado, que constituem ainda o mais característico aspecto da vida regional. A atividade pastoril é explorada na região dos Inhamuns e a agricultura do milho, algodão e feijão na serra da Ibiapaba. No alto da serra, a pecuária é também a principal atividade. Várzeas de aluvião ocorrem no Rio Jaguaribe, que corta a região de Norte a Sul.

k) - Micro-Região de Iguatú (73) - Localizada na várzea do Rio Jaguaribe, na bacia de sedimentação cortada pelo rio, a cidade de
Iguatu ocupa posição favorável em relação às vias de comunicação que cortam o Estado. A extensão das várzeas facultou o desenvolvimento das culturas do algodão herbáceo, do arroz, da canade-açúcar, do milho e do feijão. A pecuária constitui atividade menos desenvolvida que a agricultura. Jazidas de magnezita e água mineral existentes na bacia do Iguatu, são exploradas.

\section{1) - Micro-Região do Sertão do Salgado (74)} - Agricultura e pecuária são atividades dominantes no sertão do Salgado, que é formado por várzeas e trechos serranos. Entre os produtos cultivados salienta-se o algodão arbóreo.

m) - Micro-Região do Cariri (78) - Constitui importante área do Sul do Estado, tendo em Crato e Juazeiro do Norte os mais destacados núcleos da vida urbana regional. No Cariri, desde a sua ocupação, desenvolveu-se a vida agrícola, com a cana-de-açúcar e os engenhos de rapadura e aguardente, produzidos para os mercados sertanejos. Além da cana-de-açúcar, salientam-se os cultivos do algodão arbóreo, consorciado ao milho e ao feijão, nos terrenos mais secos, e a cultura do arroz nas várzeas. As pequenas propriedades $e$ os sítios têm na fruticultura e na horticultura fonte de renda. $\mathrm{Na}$ Chapada do Araripe, a mandioca e as casas de farinha constituem atividade tradicional, enquanto a fruticultura, com o abacaxi, vem sendo fomentada.

n) - Micro-Região do Sertão do Cariri (76) - Os sertões do Cariri são mais secos e possuem maiores extensões sertanejas que o Cariri úmido. $\mathrm{O}$ algodão mocó é o principal produto agrícola, consorciado ao milho e ao feijão, servindo os campos plantados ao pastejo do gado após a colheita. Nos baixios, a canadeaçúcar e os arrozais completam a paisagem. Nas serras cristalinas a vida agrícola se adensa, e na Chapada do Araripe a mandioca e as casas de farinha são traço característico.

o) - Micro-Região da Chapada do Araripe (77) - No alto da Chapada do Araripe a pecuária extensiva, a mandioca e o abacaxi são a base da vida econômica, enquanto nos piemontes secos, o algodão mocó é o principal produto agrícola, seguido pelo feijão e o milho.

p) - Micro-Região da Uruburetama (58) Situada em área próxima e ligada a Fortaleza, por rodovia asfaltada, a serra de Uruburetama constitui o principal aspecto da região, que engloba ainda trecho litorâneo e trecho sertane jo. A serra é a grande produtora de banana do Estado. Além da banana, as lavouras de subsistência nas encostas íngremes determinam sérios 

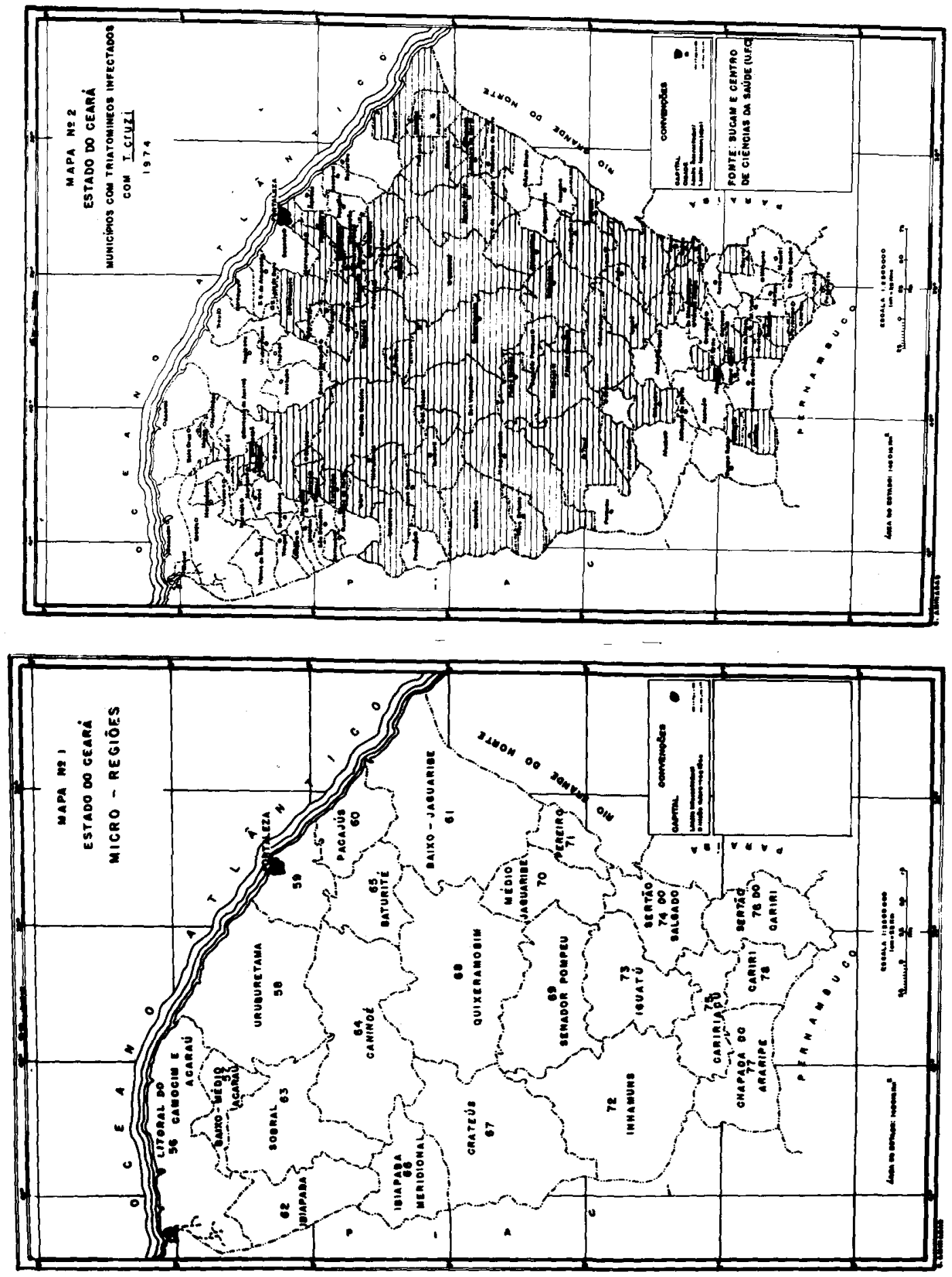
problemas de erosão dos solos. Incluem-se na região o litoral e a várzea de irrigação do Rio Curu.

q) - Micro-Região da Ibiapaba (62) - Tem como traço característico a área úmida da serra do Ibiapaba, formando brejo de altitude. Os numerosos sítios existentes refletem o fracionamento da propriedade e as elevadas densidades rurais. A cana-de-açúcar é cultivada desde o passado alimentando os primitivos engenhos de rapadura e aguardente. $O$ café, a fruticultura, $o$ milho, a mandioca e o feijão completam o quadro agrário onde, em meio aos campos de lavoura, ocorre o babaçú.

r) - Micro-Região da Ibiapaba Meridional (66) - Localizada no contato entre a Ibiapaba e os sertões próximos, inclui aspectos físicos e econômicos variados. Nos trechos serranos e nos pés da serra concentra-se a vida agrícola, em que se destacam a cana-de-açúcar, o algodão, o milho e o feijão. Na área sertaneja, a atividade predominante é a criação do gado bovino.

s) - Micro-Região da Serra do Pereiro (71) Localizada na região limítrofe com o Rio Grande do Norte, a Serra do Pereiro se enquadra entre as "serras secas" produtoras de algodão, milho e feijão. Nas extensões sertanejas, a criação de gado é a atividade principal. Os núcleos urbanos são inexpressivos.

t) - Micro-Região Serrana de Caririaçu (75) - As serras cristalinas que antecedem os relevos da Chapada do Araripe são quadro de vida agrícola, apresentando elevadas densidades de ocupação se comparadas aos sertões circundantes. Na serra de São Pedro o arroz é o principal produto agrícola, enquanto nos pés de serra e no sertão ganham ênfase o algodão arbóreo e o milho.

u) - Micro-Região do Baixo Jaguaribe (61) - A mais extensa planície aluvial do Ceará é a do rio Jaguaribe que, juntamente com a do rio Banabuiú, individualiza a Micro-Região. Elevadas densidades rurais e pequena propriedade policultora, explorando algodão, cereais e frutas, caracterizam a várzea, onde se pratica a irrigação, mediante bombeamento da água do subsolo, com cataventos. Programas de irrigação vêm sendo levados a cabo no Jaguaribe e no Banabuiú, a cargo do DNOCS, destacando-se o projeto Morada Nova, na bacia hidrográfica do Banabuiú. A grande propriedade também está presente na região, tendo no extrativismo da cera de carnaúba e no gado as suas bases econômicas.

v) - Micro-Região do Litoral de Camocim e Acaraú (56) - Ocupado desde o passado, o litoral norte teve em Camocim o porto que escoava os produtos dos sertōes do Acaraú, da Meruoca e da Ibiapaba. O extrativismo da carnaúba, o gado, a mandioca e a pesca caracterizam a vida econômica da região, de elevados coeficientes migratórios.

x) - Micro-Região do Baixo-Médio Acaraú (57) - Pequena Micro-Região que marca a transição entre a região de Sobral e o litoral de Camocim-Acaraú. Trechos de várzea, sertão e serras secas integram a área que tem na pecuária a principal atividade.

\section{INFORMAÇÕES PUBLICADAS ANTERIOR. MENTE}

A primeira referência à presença de triatomíneos no Estado do Ceará se deve a Gavião Gonzaga' que em 1921 assinalou a presença de Panstrongylus megistus e de Rhodnius prolixus, infectados pelo Trypanosoma cruzi nas zonas de Quixadá e do Carirí. Mais tarde Albuquer. que, Brito e Moraes ${ }^{1}$ referem que Fialho assinalou o $P$. megistus em Baturité e E. Chagas - Triatoma brasiliensis no Jaguaribe. Esses mesmos autores informam que em nove municipios do Vale do Cariri, da Serra da Baturité e do Baixo e Médio Jaguaribe foram examinados 1.113 triatomíneos (P. megistus, T. pseudomaculata e $T$. brasiliensis) dos quais $15,4 \%$ estavam infectados.

Em 1950, Jucá e Cunha ${ }^{12}$ referem o $P$. megistus em Quixadá e Baturité e o T. brasiliensis em Russas e Icó.

Em 1951, Machado ${ }^{10}$ assinala $P$. megistus em Redenção ( 1 em 4 positivo para $T$. cruzi).

Em 1952, Machado e Pinto ${ }^{11}$ publicaram os resultados do trabalho de reconhecimento do Serviço Nacional de Malária em 20 municípios do Estado (na época um quarto da área do Estado).

As informações obtidas estão assinaladas na Tabela 1, que registra todas as informações obtidas no passado e no presente, no Estado do Ceará.

Bustamante $^{5}$ em 1957, referiu o T. brasiliensis em 41 municípios, o $P$. megistus em 24, o $T$. pseudomaculata em 1, o $R$. nasutus em 3 e o $P$. geniculatus em 1. Certamente o último foi incorretamente identificado e é possível que se tratasse do $P$. lutzi. Os dados estão referidos na Tabela 1.

Recentemente, em 1957, Deane e Deane ${ }^{7}$ publicaram os dados referentes ao noroeste do Estado do Ceará, obtidos entre 1953 e 1957. Por essa ocasião examinaram 1.257 triatomí- 
neos com os seguintes resultados: o $T$. brasiliensis nos municípios de Sobral, Massapê, Tianguá e Viçosa; o $T$. pseudomaculata em Sobral e Viçosa, o $P$. megistus e o $P$. lutzi e o $R$. nasutus em Sobral e Massapê (Tabela 1).

Em 1963 e 1965, Alencar e cols. ${ }^{2,3,4}$ referem dados obtidos por investigações feitas pelo Instituto de Medicina Preventiva da Universidade Federal do Ceará, os quais resumemse nas Tabelas 1 a 8.

Em 1966, a Superintendência de Campanhas do Ministério da Saúde (SUCAM) ${ }^{14}$ apresentou os resultados das investigações realizadas em 70 municípios de 19 micro-regiões do Estado. Foram examinados 16.403 triatomíneos dos quais $6,7 \%$ estavam infectados por $T$. cruzi.

Corrêa ${ }^{6}$, em 1968, apresenta um informe sobre a Doença de Chagas no Brasil em que faz uma revisão sobre as informações quanto a presença de triatomíneos no Estado do Ceará, anotando as seguintes espécies: $P$. megistus, $P$. lutzi, T. brasiliensis, T. pseudomaculata, $R$. nasutus, $R$. prolixus e Psammolestes tertius. Quanto a penúltima das espécies, referida por Gonzaga9. provavelmente seria um erro de classificação, devendo-se identificá-lo com o $R$. nasutus. No amplo inquérito realizado pela SUCAM jamais foi encontrado qualquer exemplar de $R$. prolixus.

Deane e Deane ${ }^{7}$, em 1967, esclareceram essa referência e considerou o $R$. nasutus a única espécie de Rhodnius evidenciado no nordeste do País, conforme o que considerou Lent em 1948 e confirmou em 1954.

\section{INFORMAÇÕES ATUAIS}

\section{Distribuição Global}

De 1964 a 1974 foi intensificado o esforço de pesquisa com uma programação para profilaxia da Doença de Chagas no Ceará. A Tabela 9 resume toda essa atividade. Em quase 11 anos foram examinados 34.396 triatomíneos capturados dentro dos domicílios de 104 municípios do Estado.

Analisando os dados af alinhados verificamos que não foram encontrados triatomíneos ou não foram investigados nos seguintes municípios (Mapas 1 e 2): Camocim, Carnaubal, Chaval, Frecheirinha, Ibiapina, Martinópole, Moraujo, Pacujá, Porteiras, Senador Sá, Traiti e Uruoca(12).

Podemos concluir que praticamente em toda a área do Estado podemos encontrar as seguintes espécies de Triatomíneos: 1835);

a) Panstrongylus megistus (Burmeister,

b) Panstrongylus lutzi (Neiva e Pinto, 1923);

c) Rhodnius nasutus (Stal, 1859);

d) Triatoma brasiliensis (Neiva, 1911);

e) Triatoma pseudomaculata (Corrêa et Spinola, 1964).

Além dessas espécies que são encontradas dentro dos domicílios é referido também o Psammolestes tertius Lent e Jurberg 1965. Esta última é encontrada em ninhos de aves e não tem importância, portanto, na epidemiologia da Doença de Chagas. Esses hematófagos são referidos na região com as seguintes denominações: procotó, bicudo, chupão e barbeiro.

$\mathrm{Em}$ todas as casas trabalhadas as capturas rotineiras foram realizadas de modo mais ou menos uniforme dentro das casas (paredes, pilhas de materiais diversos, móveis, por trás dos móveis), com a ajuda de lanterna de pilhas. Os cômodos das casas que foram investigados são: quartos, salas, corredores, despensas, cozinhas e alpendres.

Em algumas oportunidades foi utilizado insetífugo, como a piriza, que era aspergido dentro das frestas das paredes de barro batido. Também em outras ocasiōes era soprada fumaça de cigarro.

Em 5 municípios foram capturados mais de mil exemplares: Crato, Icó, Limoeiro do Norte, Morada Nova e Nova Russas.

Em 5 municípios foram capturados entre 500 e 1000 exemplares: Baixio, Barbalha, Ipú, Itapajé e Russas. Nos demais o número de exemplares capturados variou de 1 a 496 exemplares.

$\mathrm{Na}$ maior parte das vezes essa variação se deveu a um maior esforço de captura em face da necessidade de trabalho. em zonas rurais extensas, como é o caso dos municípios do Baixo Jaguaribe onde o trabalho realizou-se por força de convênio com o Departamento Nacional de Obras Contra as Secas (DNOCS). Em outros se tinha em mira apenas a demonstração da existência ou não de triatomíneos na localidade, não se realizando maior esforço para capturar maior número de exemplares.

\section{Distribuição por espécie}

Como podemos verificar na Tabela 9, a espécie mais extensamente distribuída e mais prevalente no Estado é o $T$. brasiliensis.

Dos 34.396 exemplares de triatomíneos examinados 23.447 eram dessa espécie $(68,2 \%)$ 
distribuída em 85 municípios. Os dados históricos acumulados mostram-na em 129 municípios (Tabela 1).

A segunda espécie é o $T$. pseudomaculata $(15,6 \%$ ). Dessa espécie foram capturadas 5.359 exemplares em 74 municípios. A terceira é o $P$. megistus: 5.071 exemplares $(14,7 \%)$ em 58 municípios. Os dados históricos o mostram em $68,8 \%$ dos municípios. A quarta é o $R$. nasutus: 491 exemplares $(1,4 \%)$, em 23 municípios. Por último o $P$. lutzi: foi referido em 17 municípios nos quais foram capturados 28 exemplares $(0,1 \%)$. Essa espécie foi referida 12 vezes como exemplar único.

Os dados históricos (Tabela 1) mostram que o $R$. nasutus foi encontrado em $17,7 \%$ dos municípios e o $P$. lutzi em $18,4 \%$ dos municipios.

\section{Distribuição por micro-região}

Os dados obtidos pela SUCAM, de 1964 a 1974, constantes da Tabela 10, mostram os seguintes resultados por espécie:

a) P. megistus presente em $20 \quad(87,0 \%)$ micro-regiões;

b) P. lutzi presente em $10(43,5 \%)$ micro-regiões;

c) T. brasiliensis presente em 21 (91,3\%) micro-regiões;

d) $T$. pseudomaculata presente em 22 (95,7\%) micro-regiões;

e) $R$. nasutus presente em $10(43,5 \%) \mathrm{mi}$ cro-regiões.

Devemos assinalar que em algumas micro-regiões o esforço de capturar foi mínimo ou nulo, apresentando pequeno número de exemplares capturados: litoral de Camocim e Acaraú, Baixo-Médio Acaraú, Fortaleza, litoral de Pacajús, Ibiapaba, Sertões de Quixeramobim e Sertões de Senador Pompeu.

A distribuição por espécie nas diversas micro-regiões é a seguinte quanto à prevalência:

a) P. megistus: Cariri, Serra de Baturité, Sobral e Serrano de Caririaçu, Sertão do Cariri e Baixo Jaguaribe;

b) T. brasiliensis: Baixo Jaguaribe, Sertão do Salgado, Ibiapaba meridional, Sobral, Sertões de Crateús, Iguatu. Uruburetama, Sertão dos Inhamuns, Sertão do Cariri, Serrana de Caririaçu, Médio Jaguaribe e Sertões de Canindé;

c) T. pseudomaculata: Baixo Jaguaribe, Sertão do Salgado, Uruburetama, Serra do Pereiro, Sobral, Iguatu; be; e) P. Lutzi: Somente 28 exemplares foram capturados em todo o Estado.

\section{INFECCÃO DE TRIATOMINEOS POR $T$. CRUZI (Mapa 3)}

Como vimos, já Gonzaga em 1921 anunciava que os triatomíneos por ele vistos nas zonas de Quixadá e do Cariri estavam infectados, $e$ todos os demais pesquisadores a isso aludiram.

As investigações que deram lugar ao amplo conhecimento da distribuição de triatomíneos no Estado do Ceará, e cujos dados estão consubstanciados nas Tabelas 9,10 e 11, revelam uma taxa global de $6,9 \%$ de infecção. Essa taxa às vezes, trabalhando-se em áreas mais restritas, aparece maior, como vemos nos dados da Tabela $2(14,2 \%)$ que corresponde ao esforço realizado durante a Campanha Contra o Calazar.

Examinando separadamente por micro-região, vemos também variações. A Tabela 10 mostra-nos que duas regiões apresentam taxas de infecção muito acima da média, com capturas volumosas: Baixo Jaguaribe $(8,8 \%)$ e Sertões do Salgado $(10,2 \%)$. Muitas micro-regiões apresentaram médias muito baixas, mas as capturas também foram pouco volumosas. A menor taxa observada foi a da Serra de Caririaçu $(1,4 \%)$.

A Tabela 11 mostra-nos a variação das taxas de infecção ano por ano. As maiores taxas correspondem aos dois últimos anos, 1973 e $1974: 8,8 \%$ e $10,9 \%$, respectivamente. A menor taxa correspondeu ao ano de 1969. O gráfico 1 mostra-nos as variações.

Não podemos, entretanto, dar a essas informações um valor absoluto, pois elas podem refletir uma melhor e progressiva capacitação de pessoal adstrito a essas tarefas de investigações em laboratório. Não foi observada nenhuma correlação entre o volume de triatomíneos examinados $e$ as taxas de infecção observadas.

Devemos assinalar por fim, que as taxas globais de infecção foram acima de $10 \%$ em 12 municípios, a seguir referidos: Baixio, Baturité, Hidrolândia, Independência, Lavras da Mangabeira, Limoeiro do Norte, Palhano, Parambu, Quixeré, Russas, Sobral e Uruburetama.

\section{Taxa de infecção por espécie}

a) Triatoma brasiliensis (Mapa 11. Os dados na Tabela 2, mostram para esta espécie 13,7\% de infecção, mostrando-nos os municípios de Russas e Iguatu com cifras acima da média. Taxas mais elevadas foram observadas no Baixo 

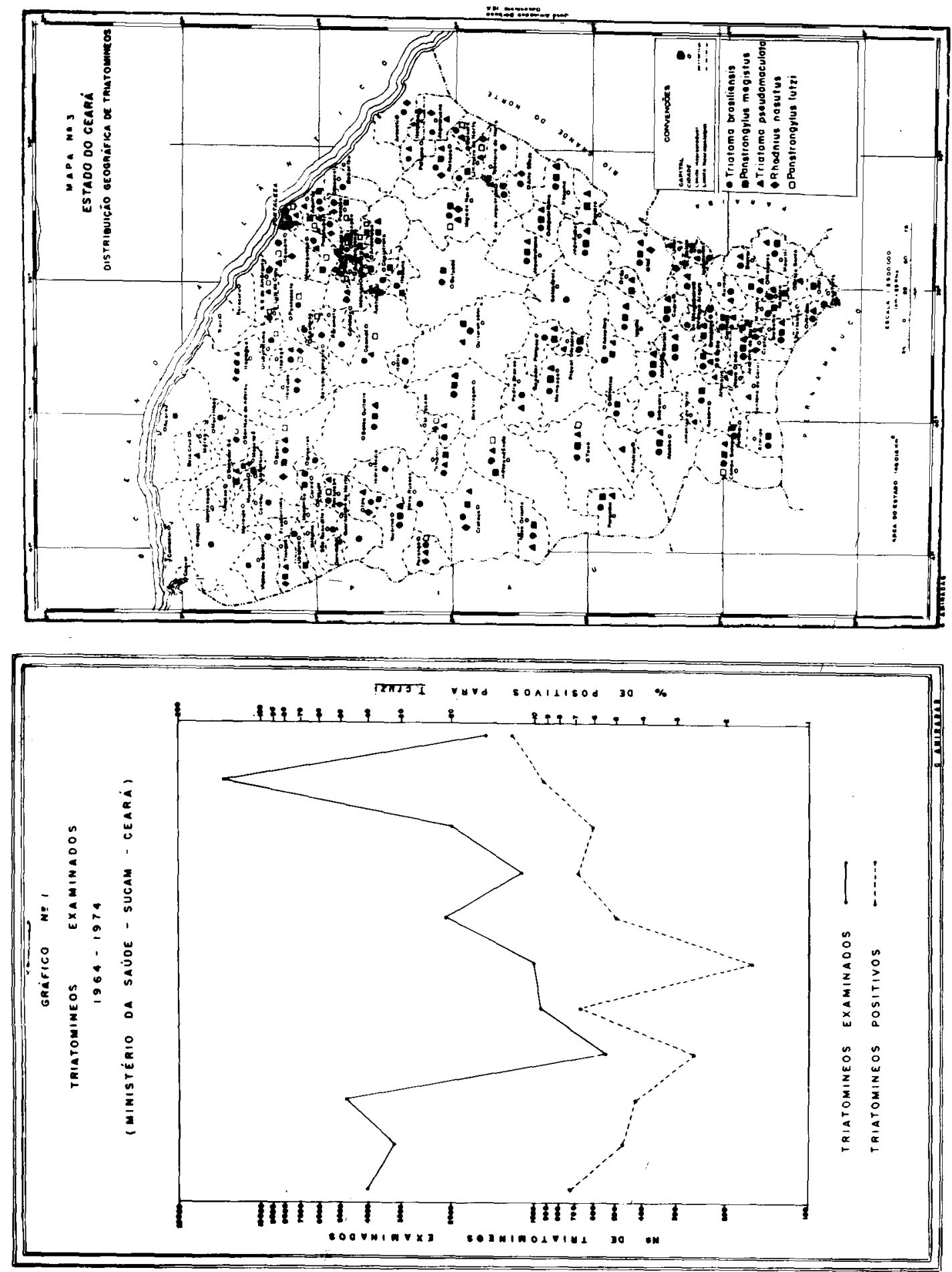


\section{TABELA 1}

Espécie de Triatom (neos Capturados em Domicflio no Estado do Ceará 1921 - 1974 (Até Novembro)

\begin{tabular}{|c|c|c|c|c|c|c|}
\hline Municípios & $\begin{array}{l}\text { T. brasi- } \\
\text { liensis }\end{array}$ & $\begin{array}{l}\text { T. pseudo- } \\
\text { maculata }\end{array}$ & $\begin{array}{c}P . \\
\text { megistus }\end{array}$ & $\begin{array}{l}P . \\
\text { lutzi }\end{array}$ & $\begin{array}{c}R . \\
\text { nasutus }\end{array}$ & $\begin{array}{l}\text { Referências } \\
\text { bibliográ- } \\
\text { ficas }\end{array}$ \\
\hline 1. Abaiára & + & + & + & & & $14^{*}$ \\
\hline 2- Acaraú & & & + & & & 14 \\
\hline 3-Acopiara & + & + & + & & & 5 \\
\hline 4. Aiuaba & + & + & + & & & 14 \\
\hline 5 - S. Alcântaras & & & + & & & 14 \\
\hline 6- Altaneira & + & + & + & & & 14 \\
\hline 7 - Alto Santo & + & + & & & + & 14 \\
\hline 8 - Antonina do Norte & + & + & + & & & $14^{*}$ \\
\hline 9 - Apuiarés & + & + & & + & & 14 \\
\hline 10. Aquiraz & $t$ & + & $t$ & & + & 4,5 \\
\hline 11 - Aracati & + & & & & + & $4,5,14$ \\
\hline 12 - Aracoiaba & + & + & + & & & 14 \\
\hline 13-Araripe & + & & & & & 5 \\
\hline 14 - Aratuba & + & & + & & & * \\
\hline 15 - Arneiroz & + & + & & & & $14^{*}$ \\
\hline 16 - Assaré & + & & + & & & 14 \\
\hline 17 - Aurora & + & + & & & & 4,14 \\
\hline 18 - Baixio & + & + & + & & & 14 \\
\hline 19 - Barbalha & + & + & + & & & $4,5^{*}$ \\
\hline 20- Barro & + & + & & & & $14^{*}$ \\
\hline 21 - Baturité & + & + & + & + & & $1,4,5,12$ \\
\hline 22 - Beberibe & & + & & & & * \\
\hline 23 - Bela Cruz & & + & & & & 4 \\
\hline 24- Boa Viagem & + & + & + & & & 4,14 \\
\hline $\begin{array}{l}25 \text { - Brejo Santo } \\
26 \text { - Camocim }\end{array}$ & & + & & & & 14 \\
\hline 27- Campos Sales & + & + & + & + & & 5,14 \\
\hline 28 - Canindé & + & + & & + & & 4,14 \\
\hline 29 - Capistrano & + & & + & & & 5 \\
\hline 30 - Caridade & + & + & & & & 14 \\
\hline 31 - Cariré & + & & + & & & 4,5 \\
\hline 32 - Caririaçu & + & + & + & & & 4,5 \\
\hline $\begin{array}{l}33 \text { - Cariús } \\
34 \text { - Carnaubal }\end{array}$ & + & + & + & & & 4,14 \\
\hline 35 - Cascavel & + & & + & & & 5,14 \\
\hline 36 - Catarina & + & + & + & & & $14 *$ \\
\hline 37 - Caucaia & + & + & & + & + & $4,5,14$ \\
\hline $\begin{array}{l}38 \text { - Cedro } \\
39 \text { - Chaval }\end{array}$ & + & + & + & & & $5 *$ \\
\hline 40 - Coreaú & + & & & & & 4 \\
\hline 41- Crateús & + & + & + & & + & $4,5,14$ \\
\hline 42- Crato & + & + & + & & + & $4 *$ \\
\hline 43 - Farias Brito & + & + & + & & & 4,14 \\
\hline $\begin{array}{l}44 \text { - Fortaleza } \\
45 \text { - Frecheirinha }\end{array}$ & + & + & & + & + & $4,5^{*}$ \\
\hline
\end{tabular}


TABELA 1 (Continuaç̃)

\begin{tabular}{|c|c|c|c|c|c|c|}
\hline Munic/pios & $\begin{array}{l}\text { T. brasi- } \\
\text { liensis }\end{array}$ & $\begin{array}{l}\text { T. pseudo- } \\
\text { maculata }\end{array}$ & $\begin{array}{c}P . \\
\text { mogistus }\end{array}$ & $\begin{array}{l}P . \\
\text { lutzi }\end{array}$ & $\begin{array}{c}R . \\
\text { nasutus }\end{array}$ & $\begin{array}{l}\text { Referências } \\
\text { bibliográ- } \\
\text { ficas }\end{array}$ \\
\hline 46 - Gen. Sampaio & + & & & & & 14 \\
\hline 47 - Granja & + & & & & & 4 \\
\hline 48 - Granjeiro & + & + & & & & $14^{*}$ \\
\hline 49-Groalras & + & & & & & 14 \\
\hline 50 - Guaraciaba do Norte & + & & + & & & * \\
\hline 51 - Guaramiranga & + & & + & & & 14 \\
\hline $\begin{array}{l}52 \text { - Hidrolândia } \\
53 \text { - Ibiapina }\end{array}$ & + & & & & & 14 \\
\hline $54 \cdot 106$ & + & + & + & & + & $4,14,12$ \\
\hline 55 - Iguatu & + & + & + & & & $4,5,14$ \\
\hline 56 - Independência & + & + & + & + & & 4,5 \\
\hline 57 - Ipaumirim & + & + & + & & & 4 \\
\hline 58- Ipú & + & + & + & & + & $4,5 *$ \\
\hline 59 - Ipueiras & + & + & + & & & $4,5,14$ \\
\hline 60 - Iracema & + & + & + & & & 4,14 \\
\hline 61 - Iraucuba & + & + & & & + & 4 \\
\hline 62 - Itaicaba & + & + & & & + & * \\
\hline 63 - I tapags & + & + & + & + & + & $4,5,14$ \\
\hline 64 - Itapipoca & + & + & + & & + & $5 *$ \\
\hline 65-Itapiuna & + & & + & & & 14 \\
\hline 66 - Itatira & + & & & & & 14 \\
\hline 67 - Jaguaretama & + & + & + & & & 4,14 \\
\hline 68 - Jaguaribara & + & + & + & & & 14 \\
\hline 69 - Jaguaribe & + & + & + & & + & $1,4,14 *$ \\
\hline 70 - Jaguaruana & + & + & & & + & $4,5 *$ \\
\hline 71 - Jardim & + & + & + & & & 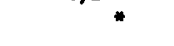 \\
\hline 72 - Jati & & & + & & & 14 \\
\hline 73 - Juazeiro do Norte & + & + & + & & & 4 \\
\hline 74 - Jucks & + & + & + & & & $4,5,14$ \\
\hline $\begin{array}{l}75 \text { - Lavras da } \\
\text { Mangabeira }\end{array}$ & + & + & & & & 4,5 \\
\hline 76 - Limoeiro do Norte & + & + & + & + & + & 4 \\
\hline $\begin{array}{l}77 \text { - Maranguape } \\
78 \text { - Marco } \\
79 \text { - Martin6pole }\end{array}$ & + & $\begin{array}{l}+ \\
+\end{array}$ & + & + & & 4,5 \\
\hline 80 - Massape & + & + & + & & + & $4,7,14$ \\
\hline 81 - Mauriti & + & + & + & & & $4 *$ \\
\hline 82 - Meruoca & + & & + & + & & $4,14^{*}$ \\
\hline 83- Milagres & + & + & + & & & 4 \\
\hline 84 - Missăo Velha & + & + & + & & + & 4,5 \\
\hline 85 - Mombeca & + & + & + & & & $4,7 *$ \\
\hline 86 - Mons. Tabosa & + & + & & + & + & 14 \\
\hline $\begin{array}{l}87 \text { - Morada Nova } \\
88 \text { - Moraujo }\end{array}$ & + & + & + & + & + & $4,14 *$ \\
\hline $\begin{array}{l}\text { 89- Morrinhos } \\
90 \text { - Mocambo }\end{array}$ & $\begin{array}{l}+ \\
+\end{array}$ & + & + & & & 14 \\
\hline 91 - Mulunge & + & & + & & & 14 \\
\hline 92 - Nova Olinda & + & + & & & & 4,14 \\
\hline 93- Nova Rusces & + & + & + & & & 7,14 \\
\hline 94 - Novo Oriente & + & + & + & & & 14 \\
\hline es:-Orbs & + & + & + & & & 14 \\
\hline
\end{tabular}


TABELA 1 (Continuaçåo)

\begin{tabular}{|c|c|c|c|c|c|c|}
\hline Municfpios & $\begin{array}{l}\text { T. brasi- } \\
\text { liensis }\end{array}$ & $\begin{array}{l}\text { T. pseudo- } \\
\text { maculata }\end{array}$ & $\begin{array}{c}P . \\
\text { megistus }\end{array}$ & $\begin{array}{c}P . \\
\text { lutzi }\end{array}$ & $\begin{array}{c}R . \\
\text { nasutus }\end{array}$ & $\begin{array}{l}\text { Referências } \\
\text { bibliográ- } \\
\text { ficas }\end{array}$ \\
\hline 96 - Pacajús & + & + & + & + & + & 4,14 * \\
\hline 97 . Pacatuba & + & + & + & + & + & 4,5 \\
\hline $\begin{array}{l}98 \text { - Pacoti } \\
99-\text { Pacujá }\end{array}$ & & & + & & & 4,5 \\
\hline 100 - Palhano & + & + & & & & 14 \\
\hline 101 - Palmácia & & + & + & + & & 4,14 \\
\hline 102 - Paracurú & & + & & & & * \\
\hline 103 - Parambú & + & + & + & & & 14 \\
\hline 104 - Paramoti & + & & & & & 14 \\
\hline 105 - Pedra Branca & + & + & & & & $5 *$ \\
\hline 106 - Penaforte & + & & + & & & 14 \\
\hline 107 - Pentecoste & + & + & & + & & 4,5 \\
\hline 108 - Pereiro & + & + & + & & & 4,14 \\
\hline 109 - Piquet Carneiro & + & + & + & & & $14 *$ \\
\hline $\begin{array}{l}\text { 110 - Poranga } \\
111 \text { - Porteiras }\end{array}$ & + & + & & + & + & $14 *$ \\
\hline 112 - Potengi & + & + & + & & & 14 \\
\hline $113 \cdot$ Quixadá & + & + & + & & & $4,5,9,12$ \\
\hline 114 - Quixeramobim & + & + & + & & & $4,5,14$ \\
\hline 115 - Quixeré & + & + & & + & & 4,14 \\
\hline 116 - Redençäo & & & + & + & + & $4,5,10^{*}$ \\
\hline 117 - Reriutaba & + & + & & & + & $5 *$ \\
\hline $118 \cdot$ Russas & + & + & + & & + & $4,5,12 *$ \\
\hline 119 - Saboeiro & + & & + & & & $5^{*}$ \\
\hline 120 - Santana do & & & & & & \\
\hline Acaraú & + & + & + & + & & $14^{*}$ \\
\hline 121 - Santana do & & & & & & \\
\hline Cariri & & + & + & & & 4,14 \\
\hline 122 - Santa Quitéria & + & + & + & & & $4,5,14$ \\
\hline 123 São Benedito & + & & + & & & 4 \\
\hline $\begin{array}{l}124 \text { - Säo Gonçalo do } \\
\text { Amarante }\end{array}$ & + & + & & + & & 4 \\
\hline $12 E$ - São João do & & & & & & \\
\hline Jaguaribe & + & + & + & & & 14 \\
\hline 126 - S.Luiz do Curu & + & + & + & + & & 4 \\
\hline 127 - Senador Pompeu & + & + & + & & & 4,5 \\
\hline 128 - Senador Sá & & & & & & \\
\hline 129. Sobral & + & + & + & + & + & $4,5,7^{*}$ \\
\hline $\begin{array}{l}130 \text { - Solonópole } \\
131 \text { - Tabuleiro do }\end{array}$ & + & & & & & 14 \\
\hline Norte & + & + & & & & 14 \\
\hline 132 - Tamboril & + & + & + & & & $5,14^{*}$ \\
\hline 133 - Tauá & + & + & + & + & & 4,5 \\
\hline 134 - Tianguá & + & + & + & & + & 4,7 \\
\hline 135 - Trairi & & & & & & \\
\hline 136 - Ubajara & + & & + & & & 4,5 \\
\hline 137 - Umari & + & + & & & . & 4,14 \\
\hline 138 - Uruburetama & + & + & + & + & & 4,5 \\
\hline 139. Uruoca & & & & & & \\
\hline 140 - Várzea Alegre & + & + & + & & & $4,5^{*}$ \\
\hline 141 - Viçosa do Ceará & & & + & & & 5,7 \\
\hline Total & 116 & 98 & 88 & 26 & 28 & - \\
\hline
\end{tabular}

* Informações do presente trabalho. 
TABELA 2

Instituto de Medicina Preventiva (U.F.Ce)

Triatomíneos Examinados para Verificar Infecção por T. cruzi

Estado do Ceará - 1955 - 1959 (Até Junho)

\begin{tabular}{|c|c|c|c|c|c|c|c|c|c|c|c|c|c|c|c|}
\hline \multirow{2}{*}{ Município } & \multicolumn{3}{|c|}{ T. brasiliensis } & \multicolumn{3}{|c|}{ T. maculata } & \multicolumn{3}{|c|}{ P. megistus } & \multicolumn{3}{|c|}{ P. lutzi } & \multicolumn{3}{|c|}{ Total } \\
\hline & $\begin{array}{l}\text { No de } \\
\text { Exam. }\end{array}$ & $\begin{array}{l}\text { Nọ de } \\
\text { Pos. }\end{array}$ & $\begin{array}{l}\% \text { de } \\
\text { Pos. }\end{array}$ & $\begin{array}{l}\text { Nọ de } \\
\text { Exam. }\end{array}$ & $\begin{array}{l}\text { No de de } \\
\text { Pos. }\end{array}$ & $\begin{array}{l}\% \text { de } \\
\text { Pos. }\end{array}$ & $\begin{array}{l}\text { Nọ de } \\
\text { Exam. }\end{array}$ & $\begin{array}{l}\text { Nọ de } \\
\text { Pos. }\end{array}$ & $\begin{array}{l}\% \text { de } \\
\text { Pos. }\end{array}$ & $\begin{array}{l}\text { Nọ de } \\
\text { Exam. }\end{array}$ & $\begin{array}{l}\text { No de } \\
\text { Pos. }\end{array}$ & $\begin{array}{l}\% \text { de } \\
\text { Pos. }\end{array}$ & $\begin{array}{l}\text { Nọ de } \\
\text { Exam. }\end{array}$ & $\begin{array}{l}\text { No de } \\
\text { Pos. }\end{array}$ & $\begin{array}{l}\% \text { de } \\
\text { Pos. }\end{array}$ \\
\hline Aracati & 7 & 2 & $\cdots$ & - & - & - & - & - & - & - & - & - & 7 & 2 & 29,0 \\
\hline Barbalha & 2 & 2 & $\ldots$ & 2 & - & - & 179 & 67 & 37,4 & - & - & - & 183 & 69 & 3,7 \\
\hline Boa Viagem & 7 & - & $\because$ & - & - & - & - & - & - & - & - & - & 7 & - & - \\
\hline Canindé & 6 & - & - & - & - & - & - & - & - & 1 & - & - & 7 & - & - \\
\hline Cariré & 50 & - & - & - & - & - & - & - & - & - & - & - & 50 & - & - \\
\hline Caririaçu & 8 & - & - & 1 & - & - & 1 & - & - & - & - & - & 10 & - & - \\
\hline Caucaia & - & - & - & 1 & - & - & - & - . & - & - & - & - & 1 & - & - \\
\hline Crato & 1 & - & - & 2 & - & - & 108 & 7 & 6,5 & - & - & - & 111 & 7 & 6,3 \\
\hline Granja & 10 & - & - & - & - & - & - & - & - & - & - & - & 10 & - & - \\
\hline Iguatu & 107 & 20 & 18,7 & 19 & 6 & 31,5 & - & - & - & - & - & - & 126 & 26 & 20,6 \\
\hline Independência & 12 & - & - & - & - & - & - & - & - & - & - & - & 12 & - & - \\
\hline Ipu & 50 & 5 & 10,0 & 2 & - & - & 9 & - & - & - & - & - & 61 & 5 & 8,3 \\
\hline loueiras & 9 & 4 & $\ldots$ & - & - & - & - & - & - & - & - & - & 9 & 4 & 44,4 \\
\hline Jaguaribe & 5 & - & - & - & - & - & - & - & - & - & - & - & 5 & - & - \\
\hline Jaguaruana & 7 & - & - & - & - & - & - & - & - & - & - & - & 7 & - & - \\
\hline $\begin{array}{l}\text { Limoeiro } \\
\text { Lavras da }\end{array}$ & 1.479 & 177 & 12,0 & 121 & - & - & 1 & - & - & - & - & - & 1.601 & 177 & 11,6 \\
\hline $\begin{array}{l}\text { Lavras da } \\
\text { Mangabeira }\end{array}$ & 74 & 5 & 6,7 & 3 & - & - & - & - & - & - & - & - & 77 & 5 & 6,5 \\
\hline Massapê & 19 & 1 & $\ldots$ & - & - & - & 2 & - & - & - & - & - & 22 & 1 & 4,8 \\
\hline Morada Nova & 107 & - & - & - & - & - & - & - & - & - & - & - & 107 & - & - \\
\hline Pacoti & 32 & - & - & - & - & - & - & - & - & - & - & - & 32 & - & - \\
\hline Quixadá & 4 & - & - & - & - & - & 1 & - & - & - & - & - & 5 & - & - \\
\hline Russas & 1.128 & 225 & 19,9 & 10 & 1 & 10,0 & - & - & - & - & - & - & 1.138 & 226 & 19,9 \\
\hline Santa Quitéria & 63 & 1 & 1,6 & - & - & - & - & - & - & - & - & - & 63 & 1 & 1,6 \\
\hline Várzea Alegre & 2 & - & - & - & - & - & - & - & - & - & - & - & 2 & - & - \\
\hline Sobral & 46 & 4 & 8,7 & 1 & - & - & - & - & - & - & - & - & 47 & 4 & 8,5 \\
\hline Ubajara & 5 & - & - & - & - & - & - & - & - & - & - & - & 5 & - & - \\
\hline Total & 3.240 & 446 & 13,7 & 162 & 7 & 4,3 & 302 & 74 & 24,5 & 1 & - & - & 3.705 & 527 & 14,2 \\
\hline
\end{tabular}


TABELA 3

Triatomineos Capturados

no Estado do Ceará e Descritos de 1955 - 1961

(Instituto de Medicina Preventiva)

\begin{tabular}{lcccc}
\hline Espécie & $\begin{array}{c}\text { No de } \\
\text { Municipios }\end{array}$ & $\begin{array}{c}\text { No de } \\
\text { Exemplares } \\
\text { Capturados }\end{array}$ & $\begin{array}{c}\text { \% de } \\
\text { Municioios } \\
\text { Estudados }\end{array}$ & $\begin{array}{c}\text { Triatomineos } \\
\text { por } \\
\text { Municipios }\end{array}$ \\
\hline T. brasiliensis & 57 & 4.925 & 81 & 86 \\
r. maculata & 32 & 764 & 46 & 17 \\
T. megistus & 22 & 1.935 & 31 & 62 \\
R. nasutus & 8 & $105^{*}$ & 11 & 13 \\
P. lutri & 14 & $70^{*}$ & 1 & 5 \\
\hline
\end{tabular}

- Tianguá com 94 exemplares

- Pacatuba com 43 exemplares

CEARÁ

TABELA 4

Alencar et al. (1965) - Rev. Bras. Malariol. D. Trop., 17(2-3):149-57

$T$. brasiliensis

\begin{tabular}{lcccc}
\hline Municípios & Periodo & $\begin{array}{c}\text { Triatomíneos } \\
\text { Examinados }\end{array}$ & $\begin{array}{c}\text { Triatomíneos } \\
\text { Infectados }\end{array}$ & $\%$ \\
\hline Aracati & $1955 / 1959$ & 7 & 2 & 194,6 \\
\hline Limoeiro & $\begin{array}{l}1955 / 1959 \\
1963 / 1964\end{array}$ & 1.507 & 12,9 \\
\hline Morada Nova & $1955 / 1959$ & 107 & 240 & 19,7 \\
\hline Russas & $\begin{array}{l}1955 / 1959 \\
1963 / 1964\end{array}$ & 1.216 & 436 & 15,4 \\
\hline
\end{tabular}


CEARÁ

TABELA 5

Alencar et al. (1963) - Rev. Bras. Malariol. D. Trop., 15(4):551-65

T. pseudomaculata

\begin{tabular}{lcccc}
\hline Municípios & Periodo & $\begin{array}{c}\text { Triatomíneos } \\
\text { Examinados }\end{array}$ & $\begin{array}{c}\text { Triatomíneos } \\
\text { Infectados }\end{array}$ & $\%$ \\
\hline Barbalha & $1954 / 1962$ & 43 & - & - \\
\hline Baturité & $1954 / 1962$ & 112 & 9 & 8,0 \\
\hline Crato & $1954 / 1962$ & 169 & 3 & 1,8 \\
\hline & Total & 324 & 12 & 3,7 \\
\hline
\end{tabular}

CEARA

TABELA 6

Alencar et al. (1965) - Rev. Bras. Malariol. D. Trop., 17(2-3):149-57

T. pseudomaculata

\begin{tabular}{lcccc}
\hline Municípios & Período & $\begin{array}{c}\text { Triatomineos } \\
\text { Examinados }\end{array}$ & $\begin{array}{c}\text { Triatomineos } \\
\text { Infectados }\end{array}$ & $\%$ \\
\hline Aracati & $1955 / 1959$ & 2 & - & - \\
\hline Limoeiro & $1955 / 1959$ & 121 & - & 9.1 \\
\hline Russas & $\begin{array}{l}1955 / 1959 \\
1963 / 1964\end{array}$ & 11 & 1 & 0.7 \\
\hline & Total & 134 & 1 & \\
\hline
\end{tabular}


CEARÄ

TABELA 7

Alencar et al. (1963) - Rev. Bras. Malariol. D. Trop., 15(4):551-65

P. megistus

\begin{tabular}{lcccc}
\hline Municípios & Período & $\begin{array}{c}\text { Triatomineos } \\
\text { Examinados }\end{array}$ & $\begin{array}{c}\text { Triatomíneos } \\
\text { Infectados }\end{array}$ & $\%$ \\
\hline Aratuba & $1954 / 1962$ & 35 & 1 & 2,9 \\
\hline Barbalha & $1954 / 1962$ & 126 & 72 & 57,1 \\
\hline Baturité & $1954 / 1962$ & 452 & 19 & 4,2 \\
\hline Crato & $1954 / 1962$ & 786 & 72 & 9,2 \\
\hline Pacoti & $1954 / 1962$ & 55 & 164 & - \\
\hline
\end{tabular}

TABELA 8

Triatomíneos Infectados por Trypanosoma Cruzi

Estado do Ceará

(Dados Informados pela SUCAM - Ministério da Saúde - 1966)

\begin{tabular}{|c|c|c|c|c|c|}
\hline \multirow{2}{*}{ Micro-Regičes } & \multirow{2}{*}{$\begin{array}{c}\text { No de } \\
\text { Municí- } \\
\text { pios } \\
\text { pesquisados }\end{array}$} & \multicolumn{3}{|c|}{ No de Triatomíneos } & \multirow{2}{*}{$\begin{array}{l}\text { Municípios de maior } \\
\text { Positividade }\end{array}$} \\
\hline & & $\begin{array}{l}\text { Exami- } \\
\text { nados }\end{array}$ & $\begin{array}{l}\text { Posi- } \\
\text { tivos }\end{array}$ & $\begin{array}{c}\% \text { de } \\
\text { Positivos }\end{array}$ & \\
\hline Ibiapaba Meridional & 1 & 1.345 & 49 & 3,6 & - \\
\hline Sertão de Crateús & 5 & 1.383 & 87 & 6,3 & Independência \\
\hline Sertão de Quixeramobim & 4 & 550 & 52 & 9,5 & Boa Viagem, Quixadá \\
\hline Sertão de Senador Pompeu & 5 & 147 & 42 & 28,6 & $\begin{array}{l}\text { Mombaça, Solonópole, } \\
\text { P. Carneiro, S. Pompeu }\end{array}$ \\
\hline Médio Jaguaribe & 2 & 380 & 13 & 3,4 & Jaguaretama \\
\hline Serra do Pereiro & 1 & 275 & 7 & 2,5 & - \\
\hline Sertão de Inhamuns & 2 & 304 & 30 & 9,9 & Cococí, Parambu \\
\hline Iguatú & 2 & 704 & 28 & 4,0 & - \\
\hline Litoral Camocim & 1 & 1 & 1 & $\ldots$ & - \\
\hline Uruburetama & 1 & 93 & 1 & 1,1 & - \\
\hline Fortaleza & 3 & 41 & 5 & 1,2 & - \\
\hline Baixo Jaguaribe & 9 & 1.814 & 193 & 10,6 & $\begin{array}{l}\text { Tabuleiro do Norte, } \\
\text { Russas, Limoeiro do } \\
\text { Norte, Palhano }\end{array}$ \\
\hline Sobral & 6 & 1.230 & 40 & 3,3 & Sobral \\
\hline Serra de Baturité & 9 & 877 & 57 & 6,5 & Baturité \\
\hline Sertão do Salgado & 6 & 954 & 102 & 10,7 & $\begin{array}{l}\text { Lavras da Mangabeira } \\
\text { Baixio }\end{array}$ \\
\hline Serra de Caririaçú & 3 & 238 & 49 & 20,6 & Farias Brito \\
\hline Sertão do Cariri & 4 & 431 & 22 & 5,1 & . - \\
\hline Chapada do Araripe & 2 & 78 & 3 & 3,8 & - \\
\hline Cariri & 4 & 2.052 & 110 & 5,4 & Barbalha \\
\hline Total & 70 & 16.403 & 1.103 & 6,7 & 19 \\
\hline
\end{tabular}


TABELA 9

Triatomíneos Examinados no Laboratório da SUCAM - Ceará, no Período 1964 - 1974 (*)

\begin{tabular}{|c|c|c|c|c|c|c|c|c|c|c|c|c|c|c|c|c|c|c|}
\hline \multirow{2}{*}{ Municípios } & \multicolumn{3}{|c|}{ P. megistus } & \multicolumn{3}{|c|}{ P. lutzi } & \multicolumn{3}{|c|}{ T. brasiliensis } & \multicolumn{3}{|c|}{ T. pseudomaculata } & \multicolumn{3}{|c|}{ R. nasutus } & \multicolumn{3}{|c|}{ Total } \\
\hline & Exam. & Pos. & $\%$ & Exam. & Pos. & $\%$ & Exam. & Pos. & $\%$ & Exam. & Pos. & $\%$ & Exam. & Pos. & $\%$ & Exam. & Pos. & $\%$ \\
\hline Abaiara & 11 & - & - & - & - & - & 1 & - & - & 11 & - & - & - & - & - & 23 & - & - \\
\hline Acopiara & 1 & - & - & - & - & - & 72 & 3 & 4,2 & 50 & 3 & 6,0 & - & - & - & 123 & 6 & 4,9 \\
\hline Aiuaba & 12 & - & - & - & - & - & 39 & - & - & 4 & - & - & - & - & - & 55 & - & - \\
\hline Alcântaras & 2 & - & - & - & - & - & - & - & - & - & - & - & - & - & - & 2 & - & - \\
\hline Altaneira & 7 & - & - & - & - & - & 1 & - & - & 12 & 1 & $\ldots$ & - & - & - & 20 & 1 & 5,0 \\
\hline Alto Santo & - & - & - & - & - & - & 92 & - & - & 59 & - & - & 1 & - & - & 152 & - & - \\
\hline \multicolumn{19}{|l|}{ Antonina do } \\
\hline Norte & 3 & 1 & $\ldots$ & - & - & - & 7 & - & - & - & - & - & - & - & - & 10 & 1 & $\ldots$ \\
\hline Apuiarés & - & - & - & 1 & - & - & 10 & - & - & 36 & - & - & - & - & - & 47 & - & - \\
\hline Aquiraz & 4 & - & - & - & - & - & - & - & - & - & - & - & - & - & - & 4 & - & - \\
\hline Aracati & - & - & - & - & - & - & 26 & - & - & - & - & - & 9 & - & - & 35 & - & - \\
\hline Aracoiaba & 78 & - & - & - & - & - & 34 & 2 & 5,9 & 7 & - & - & - & - & - & 119 & 2 & 1,7 \\
\hline Araripe & 16 & 1 & $\ldots$ & - & - & - & - & - & - & - & - & - & - & - & - & 16 & 1 & $\ldots$ \\
\hline Arneiroz & - & - & - & - & - & - & 110 & 3 & 2,7 & 16 & - & - & - & - & - & 126 & 3 & 2,4 \\
\hline Assaré & 36 & - & - & - & - & - & 33 & - & - & - & - & - & - & - & - & 69 & - & - \\
\hline Aurora & - & - & - & - & - & - & 54 & - & - & 20 & - & - & - & - & - & 74 & - & - \\
\hline Baixio & 6 & - & - & - & - & - & 516 & 77 & 14,9 & 211 & 21 & 10,0 & - & - & - & 733 & 98 & 13,4 \\
\hline Barbalha & 780 & 67 & 8,6 & - & - & - & 64 & 1 & 1,6 & 126 & 7 & 5,6 & 3 & - & - & 973 & 75 & 7,6 \\
\hline Barro & - & - & - & - & - & - & 191 & 14 & 7,3 & 83 & 2 & 2,4 & - & - & - & 274 & 16 & 5,8 \\
\hline Baturité & 41 & 7 & 17,1 & - & - & - & - & - & - & - & - & - & - & - & - & 41 & 7 & 17,1 \\
\hline Beberibe & - & - & - & - & - & - & - & - & - & 1 & - & - & - & - & - & 1 & - & - \\
\hline
\end{tabular}

(*) Até o mês de novembro 
TABELA 9 (Continuação)

\begin{tabular}{|c|c|c|c|c|c|c|c|c|c|c|c|c|c|c|c|c|c|c|}
\hline \multirow{2}{*}{ Munic/pios } & \multicolumn{3}{|c|}{ P. megistus } & \multicolumn{3}{|c|}{ P. Iutzi } & \multicolumn{3}{|c|}{ T. brasiliensis } & \multicolumn{3}{|c|}{ T. pseudomaculata } & \multicolumn{3}{|c|}{ R. nasutus } & \multicolumn{3}{|c|}{ Total } \\
\hline & Exam. & Pos. & $\%$ & Exam. & Pos. & $\%$ & Exam. & Pos. & $\%$ & Exam. & Pos. & $\%$ & Exam. & Pos. & $\%$ & Exam. & Pos. & $\%$ \\
\hline Brejo Santo & - & - & - & - & - & - & - & - & - & 2 & - & - & - & - & - & 2 & - & - \\
\hline Campos Sales & 16 & - & - & 1 & - & - & 22 & - & - & - & - & - & - & - & - & 39 & - & - \\
\hline Canindé & - & - & - & - & - & - & 2 & - & - & - & - & - & - & - & - & 2 & - & - \\
\hline Cariré & - & - & - & - & - & - & 177 & 11 & 6,2 & - & - & - & - & - & - & 177 & 11 & 6,2 \\
\hline Caririaçú & 23 & - & - & - & - & - & 7 & - & - & - & - & - & - & - & - & 30 & - & - \\
\hline Cariús & 14 & - & - & - & - & - & 12 & - & - & 2 & - & - & - & - & - & 25 & - & - \\
\hline Cascavel & 1 & - & - & - & - &.- & - & - & - & - & - & - & - & - & - & 1 & - & - \\
\hline Catarina & 6 & - & - & - & - & - & - & - & - & 9 & - & - & - & - & - & 15 & - & - \\
\hline Caucaia & - & - & - & - & - & - & 4 & - & - & - & - & - & 17 & - & - & 21 & - & - \\
\hline Crateús & 2 & - & - & - & - & - & 356 & 6 & 1,7 & 5 & - & - & 2 & - & - & 365 & 6 & 1,6 \\
\hline Crato & 2.814 & 75 & 2,7 & - & - & - & 11 & - & - & 41 & 4 & 9,8 & 5 & - & - & 2.871 & 79 & 2,8 \\
\hline Cedro & - & - & - & - & - & - & 14 & 1 & $\ldots$ & 1 & - & - & - & - & - & 15 & 1 & $\ldots$ \\
\hline Farias Brito & 102 & 1 & $\pm 1,0$ & - & - & - & 153 & 3 & $\pm 2,0$ & 19 & - & - & - & - & - & 274 & 4 & 1,5 \\
\hline Fortaleza & - & - & - & 2 & 1 & $\ldots$ & - & - & - & - & - & - & 5 & 2 & 28,6 & 7 & 3 & $\ldots$ \\
\hline General Sampaio & - & - & - & - & - & - & 28 & - & - & - & - & - & - & - & - & 28 & - & - \\
\hline Groairas & - & $-{ }^{\cdot}$ & - & - & - & - & 13 & 1 & $\cdots$ & - & - & - & - & - & - & 13 & 1 & $\ldots$ \\
\hline $\begin{array}{l}\text { Guaraciaba do } \\
\text { Norte }\end{array}$ & 1 & - & - & - & - & - & - & - & - & $i$ & - & - & - & - & - & 2 & - & - \\
\hline Hidrolândia & - & - & - & - & - & - & 86 & 9 & 10,5 & - & - & - & - & - & - & 86 & 9 & 10,5 \\
\hline Icó & 1 & - & - & - & - & - & 3.759 & 392 & 10,4 & 509 & 18 & 3,5 & 12 & - & - & 4.281 & 410 & 9,6 \\
\hline Iguatú & - & - & - & - & - & - & 358 & 14 & 3,9 & 40 & 3 & 7,5 & - & - & - & 398 & 17 & 4,3 \\
\hline Independência & - & - & - & 1 & 1 & $\ldots$ & 394 & 61 & 15,5 & 2 & 1 & $\ldots$ & - & - & - & 397 & 63 & 15,9 \\
\hline Ipaumirim & 10 & 1 & $\ldots$ & - & - & - & 91 & 7 & 7,7 & 25 & 1 & 4,0 & - & - & - & 126 & 9 & 7,1 \\
\hline Ipú & 40 & - & - & 1 & - & - & 587 & 6 & 1,0 & 1 & - & - & 1 & - & - & 630 & 6 & 1,0 \\
\hline
\end{tabular}


TABELA 9 (Continuação)

\begin{tabular}{|c|c|c|c|c|c|c|c|c|c|c|c|c|c|c|c|c|c|c|}
\hline \multirow{2}{*}{ Municipios } & \multicolumn{3}{|c|}{ P. megistus } & \multicolumn{3}{|c|}{ P. Iutzi } & \multicolumn{3}{|c|}{ T. brasiliensis } & \multicolumn{3}{|c|}{ T. pseudomaculata } & \multicolumn{3}{|c|}{ R. nasutus } & \multicolumn{3}{|c|}{ Total } \\
\hline & Exam. & Pos. & $\%$ & Exam. & Pos. & $\%$ & Exam. & Pos. & $\%$ & Exam. & Pos. & $\%$ & Exam. & Pos. & $\%$ & Exam. & Pos. & $o_{0}$ \\
\hline Ipueiras & 10 & - & - & - & - & - & 74 & - & - & 2 & - & - & - & - & - & 86 & - & - \\
\hline Iracema & 24 & - & - & - & - & - & 40 & - & - & 87 & - & - & - & - & - & 151 & - & - \\
\hline Irauçuba & - & - & - & - & - & - & 80 & 1 & 1,3 & 68 & 2 & 2,9 & 1 & - & - & 149 & 3 & 2,0 \\
\hline Itaiçaba & - & - & - & - & - & - & 437 & 29 & 6,6 & 1 & - & - & 1 & - & - & 439 & 29 & 6,6 \\
\hline Itapagé & 2 & - & - & - & - & - & 106 & - & - & 452 & - & - & 225 & - & - & 785 & - & - \\
\hline I tapipoca & 1 & - & - & - & - & - & 154 & - & - & 40 & - & - & 4 & - & - & 199 & - & - \\
\hline Jaguaribara & 10 & - & - & - & - & - & 77 & - & - & 16 & - & - & - & - & - & 103 & - & - \\
\hline Jaguaribe & 1 & - & - & - & - & - & 190 & 5 & 2,6 & 154 & 3 & 1,9 & 2 & - & - & 347 & 8 & 2,3 \\
\hline Jaguaruana & - & - & - & - & - & - & 475 & 24 & 5,1 & 5 & 1 & $\ldots$ & 1 & - & - & 481 & 25 & 5,2 \\
\hline Jardim & 304 & 17 & 5,6 & - & - & - & - & - & - & 10 & - & - & - & - & - & 314 & 17 & 5,4 \\
\hline Jati & 47 & 3 & 6,4 & - & - & - & - & - & - & - & - & - & - & - & - & 47 & 3 & 6,4 \\
\hline \multicolumn{19}{|l|}{ Juazeiro do } \\
\hline Norte & 2 & - & - & - & - & - & 25 & 1 & 4,0 & 4 & 1 & - & - & - & - & 31 & 2 & 6,5 \\
\hline Jucás & 15 & - & - & - & - & - & 66 & - & - & 4 & - & - & - & - & - & 85 & - & - \\
\hline \multicolumn{19}{|l|}{ Lavras da } \\
\hline Mangabeira & - & - & - & - & - & - & 149 & 24 & 16,1 & 8 & - & - & - & - & - & 157 & 24 & 15,3 \\
\hline \multicolumn{19}{|l|}{ Limoeiro do } \\
\hline Norte & 27 & 7 & 25,9 & 3 & 1 & 33,3 & 4.155 & 617 & 14,8 & 532 & 74 & 13,9 & 3 & - & - & 4.720 & 699 & 14,8 \\
\hline Maranguape & - & - & - & 1 & - & - & 27 & 1 & 3,7 & 1 & - & - & - & - & - & 29 & 1 & 3,5 \\
\hline Marco & - & - & - & - & - & - & - & - & - & 1 & 1 & $\ldots$ & - & - & - & 1 & 1 & $\ldots$ \\
\hline Massapê & 8 & - & - & - & - & - & 11 & - & - & 17 & - & - & - & - & - & 36 & - & - \\
\hline Mauriti & 2 & - & - & - & - & - & 65 & 4 & 6,2 & 26 & 1 & 3,8 & - & - & - & 93 & 5 & 5,9 \\
\hline Meruoca & 212 & - & - & 1 & 1 & $\cdots$ & - & - & - & - & - & - & - & - & - & 213 & 1 & 0,5 \\
\hline Milagres & - & - & - & - & - & - & 11 & - & - & 1 & - & - & - & - & - & 12 & - & - \\
\hline Missão Velha & 20 & - & - & - & - & - & 5 & - & - & 1 & - & - & - & - & - & 26 & - & - \\
\hline Monsenhor Tabosa & - & - & - & 6 & - & - & 52 & 1 & 1,9 & 54 & 4 & 7,4 & 10 & - & - & 122 & 5 & 4,1 \\
\hline
\end{tabular}


TABELA 9 (Continuação)

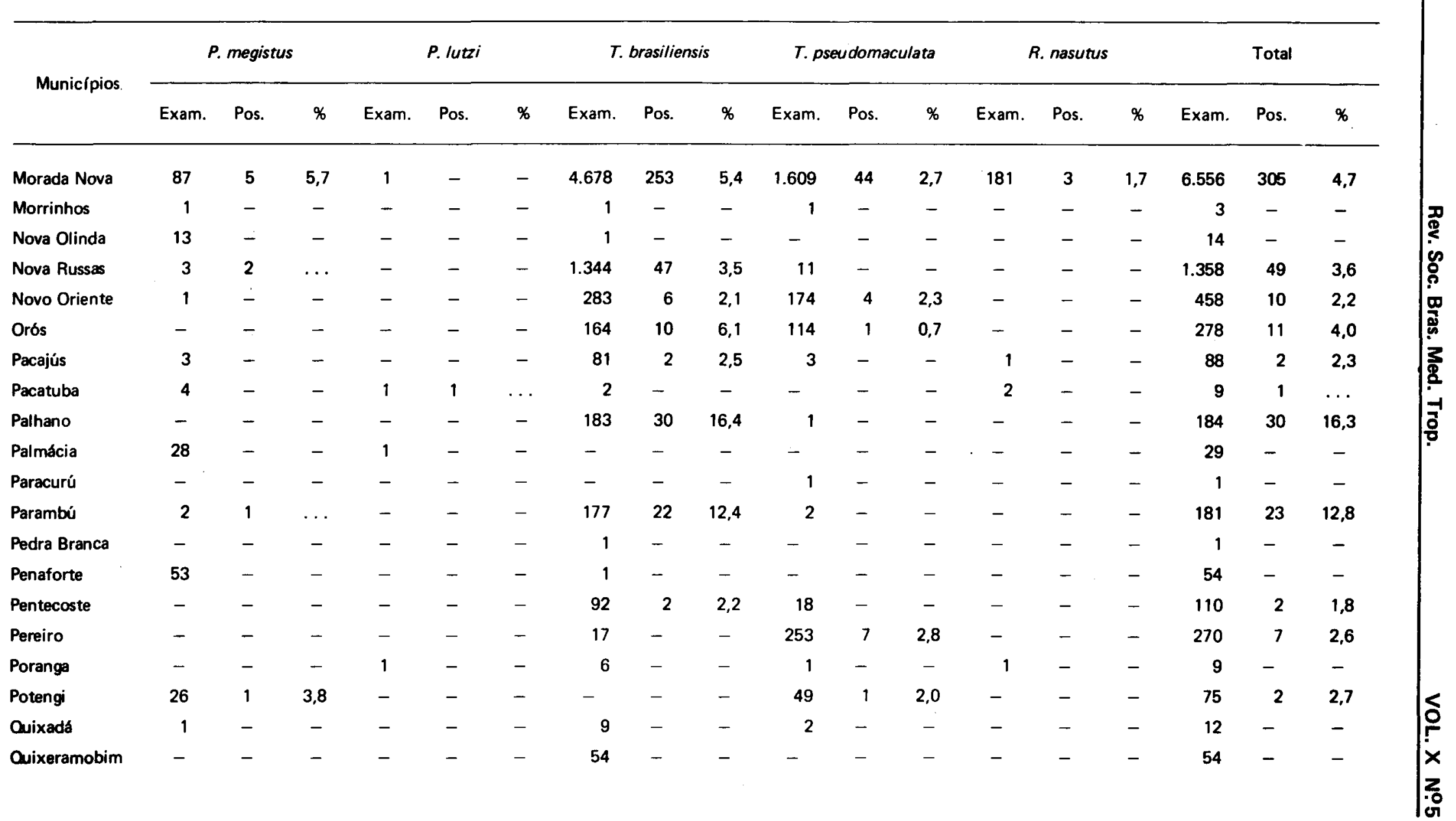


TABELA 9 (Continuação)

\begin{tabular}{|c|c|c|c|c|c|c|c|c|c|c|c|c|c|c|c|c|c|c|}
\hline \multirow{2}{*}{ Municipios. } & \multicolumn{3}{|c|}{ P. megistus } & \multicolumn{3}{|c|}{ P. lutzi } & \multicolumn{3}{|c|}{ T. brasiliensis } & \multicolumn{3}{|c|}{ T. pseudomaculata } & \multicolumn{3}{|c|}{ R. nasutus } & \multicolumn{3}{|c|}{ Total } \\
\hline & Exam. & Pos. & $\%$ & Exam. & Pos. & $\%$ & Exam. & Pos. & $\%$ & Exam. & Pos. & $\%$ & Exam. & Pas. & $\%$ & Exam. & Pos. & $\%$ \\
\hline Morada Nova & 87 & 5 & 5,7 & 1 & - & - & 4.678 & 253 & 5,4 & 1.609 & 44 & 2,7 & 181 & 3 & 1,7 & 6.556 & 305 & 4,7 \\
\hline Morrinhos & 1 & - & - & - & - & - & 1 & - & - & 1 & - & - & - & - & - & 3 & - & - \\
\hline Nova Olinda & 13 & - & - & - & - & - & 1 & - & - & - & - & - & - & - & - & 14 & - & - \\
\hline Nova Russas & 3 & 2 & $\ldots$ & - & - & - & 1.344 & 47 & 3,5 & 11 & - & - & - & - & - & 1.358 & 49 & 3,6 \\
\hline Novo Oriente & 1 & $\dot{-}$ & - & - & - & - & 283 & 6 & 2,1 & 174 & 4 & 2,3 & - & - & - & 458 & 10 & 2,2 \\
\hline Oros & - & - & - & - & - & - & 164 & 10 & 6,1 & 114 & 1 & 0,7 & - & - & - & 278 & 11 & 4,0 \\
\hline Pacajüs & 3 & - & - & - & - & - & 81 & 2 & 2,5 & 3 & - & - & 1 & - & - & 88 & 2 & 2,3 \\
\hline Pacatuba & 4 & - & - & 1 & 1 & $\ldots$ & 2 & - & - & - & - & - & 2 & - & - & 9 & 1 & $\ldots$ \\
\hline Palhano & - & - & - & - & - & - & 183 & 30 & 16,4 & 1 & - & - & - & - & - & 184 & 30 & 16,3 \\
\hline Palmácia & 28 & - & - & 1 & - & - & - & - & - & - & - & - & - & - & - & 29 & - & - \\
\hline Paracurú & - & - & - & - & - & - & - & - & - & 1 & - & - & - & - & - & 1 & - & - \\
\hline Parambú & 2 & 1 & $\ldots$ & - & - & - & 177 & 22 & 12,4 & 2 & - & - & - & - & - & 181 & 23 & 12,8 \\
\hline Pedra Branca & - & - & - & - & - & - & 1 & - & - & - & - & - & - & - & - & 1 & - & - \\
\hline Penaforte & 53 & - & - & - & - & - & 1 & - & - & - & - & - & - & - & - & 54 & - & - \\
\hline Pentecoste & - & - & - & - & - & - & 92 & 2 & 2,2 & 18 & - & - & - & - & - & 110 & 2 & 1,8 \\
\hline Pereiro & - & - & - & - & - & - & 17 & - & - & 253 & 7 & 2,8 & - & - & - & 270 & 7 & 2,6 \\
\hline Poranga & - & - & - & 1 & - & - & 6 & - & - & 1 & - & - & 1 & - & - & 9 & - & - \\
\hline Potengi & 26 & 1 & 3,8 & - & - & - & - & - & - & 49 & 1 & 2,0 & - & - & - & 75 & 2 & 2,7 \\
\hline Cuixadá & 1 & - & - & - & - & - & 9 & - & - & 2 & - & - & - & - & - & 12 & - & - \\
\hline Quixeramobim & - & - & - & - & - & - & 54 & - & - & - & - & - & - & - & - & 54 & - & - \\
\hline
\end{tabular}


TABELA 9 (Continuação)

\begin{tabular}{|c|c|c|c|c|c|c|c|c|c|c|c|c|c|c|c|c|c|c|}
\hline \multirow{2}{*}{ Municípios } & \multicolumn{3}{|c|}{ P. megistus } & \multicolumn{3}{|c|}{ P. lutzi } & \multicolumn{3}{|c|}{ T. brasiliensis } & \multicolumn{3}{|c|}{ T. pseudomaculata } & \multicolumn{3}{|c|}{ R. nasutus } & \multicolumn{3}{|c|}{ Total } \\
\hline & Exam. & Pos. & $\%$ & Exam. & Pos. & $\%$ & Exam. & Pos. & $\%$ & Exam. & Pos. & $\%$ & Exam. & Pos. & $\%$ & Exam. & Pos. & $\%$ \\
\hline Quixeré & - & - & - & 3 & - & - & 301 & 37 & 12,3 & 1 & - & - & - & - & - & 305 & 37 & 12,1 \\
\hline Redençæo & 98 & 7 & 7.1 & - & - & - & - & - & - & - & - & - & - & - & - & 98 & 7 & 7,1 \\
\hline Reriutaba & - & - & - & - & - & - & 339 & 9 & 2,7 & 155 & - & - & 2 & - & - & 496 & 9 & 1,8 \\
\hline Russas & - & - & - & - & - & - & 967 & 114 & 11,8 & 8 & - & - & - & - & - & 975 & 114 & 11,7 \\
\hline Saboeiro & 9 & - & - & - & - & - & 94 & - & - & - & - & - & - & - & - & 103 & - & - \\
\hline $\begin{array}{l}\text { Santa Quitéria } \\
\text { Santana do }\end{array}$ & - & - & - & - & - & - & 108 & 3 & 2,8 & 19 & - & - & - & - & - & 127 & 3 & 2,4 \\
\hline $\begin{array}{c}\text { Acaraú } \\
\text { Santana do }\end{array}$ & - & - & - & 2 & - & - & 19 & - & - & 4 & - & - & - & - & - & 25 & - & - \\
\hline $\begin{array}{l}\text { Cariri } \\
\text { S. G. do }\end{array}$ & 3 & - & - & - & - & - & - & - & - & - & - & - & - & - & - & 3 & - & - \\
\hline $\begin{array}{l}\text { Amarante } \\
\text { S. J. do }\end{array}$ & - & - & - & - & - & - & 6 & - & - & 1 & - & - & - & - & - & 7 & - & - \\
\hline $\begin{array}{l}\text { Jaguaribe } \\
\text { São Luis do }\end{array}$ & 6 & 1 & . & - & - & - & 182 & 9 & 4,9 & 1 & - & - & - & - & - & 189 & 10 & 5,3 \\
\hline Curú & - & - & - & - & - & - & 2 & - & - & 18 & - & - & - & - & - & 20 & - & - \\
\hline $\begin{array}{l}\text { Sobral } \\
\text { Tabuleiro do }\end{array}$ & - & - & - & 1 & - & - & 212 & 26 & 12,3 & 94 & 19 & 20,2 & 2 & - & - & 309 & 45 & 14,6 \\
\hline Norte & - & - & - & - & - & - & 279 & 10 & 3,4 & 11 & - & - & - & - & - & 290 & 10 & 3,4 \\
\hline Tamboril & 3 & - & - & - & - & - & 99 & 6 & 6,1 & 1 & - & - & - & - & - & 103 & 6 & 5,8 \\
\hline Tauá & - & - & - & 1 & - & - & 53 & 3 & 5,2 & - & - & - & - & - & - & 54 & 3 & 5,6 \\
\hline Umari & - & - & - & - & - & - & 22 & 1 & 4,5 & 26 & 2 & 7,7 & - & - & - & 48 & 3 & 6,4 \\
\hline Uruburetama & - & - & - & - & - & - & 57 & 23 & 40,4 & - & - & - & - & - & - & 57 & 23 & 40,4 \\
\hline Várzea Alegre & 18 & - & - & - & - & - & 90 & - & - & 4 & 1 & $\ldots$ & - & - & - & 112 & 1 & 1,1 \\
\hline Total & 5.071 & 197 & 3,9 & 28 & 5 & 17,9 & 23.447 & 1.931 & 8,2 & 5.359 & 227 & 4,2 & 491 & 5 & 1,0 & 34.396 & 2.365 & 6,9 \\
\hline $\begin{array}{l}\text { Total de } \\
\text { Municipios com } \\
\text { Triatomíneos }\end{array}$ & 58 & & & 17 & & & 85 & & & 74 & & & 23 & & & 104 & & \\
\hline
\end{tabular}


TABELA 9 (Continuação)

\begin{tabular}{|c|c|c|c|c|c|c|c|c|c|c|c|c|c|c|c|c|c|c|}
\hline \multirow{2}{*}{ Municlpios } & \multicolumn{3}{|c|}{ P. megistus } & \multicolumn{3}{|c|}{ P. lutzi } & \multicolumn{3}{|c|}{ T. brasiliensis } & \multicolumn{3}{|c|}{ T. pseudomaculata } & \multicolumn{3}{|c|}{ R. nasutus } & \multicolumn{3}{|c|}{ Total } \\
\hline & Exam. & Pos. & $\%$ & Exam. & Pos. & $\%$ & Exam. & Pos. & $\%$ & Exam. & Pos. & $\%$ & Exam. & Pos. & $\%$ & Exam. & Pos. & $\%$ \\
\hline Quixeré & - & - & - & 3 & - & - & 301 & 37 & 12,3 & 1 & - & - & - & - & - & 305 & 37 & 12,1 \\
\hline Redenção & 98 & 7 & 7,1 & - & - & - & - & - & - & - & - & - & - & - & - & 98 & 7 & 7,1 \\
\hline Reriutaba & - & - & - & - & - & - & 339 & 9 & 2.7 & 155 & - & - & 2 & - & - & 496 & 9 & 1,8 \\
\hline Russas & - & - & - & - & - & - & 967 & 114 & 11,8 & 8 & - & - & - & - & - & 975 & 114 & 11,7 \\
\hline Saboeiro & 9 & - & - & - & - & - & 94 & - & - & - & - & - & - & - & - & 103 & - & - \\
\hline $\begin{array}{l}\text { Santa Quitéria } \\
\text { Santana do }\end{array}$ & - & - & - & - & - & - & 108 & 3 & 2,8 & 19 & - & - & - & - & - & 127 & 3 & 2,4 \\
\hline $\begin{array}{c}\text { Acaraú } \\
\text { Santana do }\end{array}$ & - & - & - & 2 & - & - & 19 & - & - & 4 & - & - & - & - & - & 25 & - & - \\
\hline $\begin{array}{l}\text { Cariri } \\
\text { S. G. do }\end{array}$ & 3 & - & - & - & - & - & - & - & - & - & - & - & - & - & - & 3 & - & - \\
\hline $\begin{array}{l}\text { Amarante } \\
\text { S. J. do }\end{array}$ & - & - & - & - & - & - & 6 & - & - & 1 & - & - & - & - & - & 7 & - & - \\
\hline $\begin{array}{l}\text { Jaguaribe } \\
\text { São Luís do }\end{array}$ & 6 & 1 & $\ldots$ & - & - & - & 182 & 9 & 4,9 & 1 & - & - & - & - & - & 189 & 10 & 5,3 \\
\hline Curú & - & - & - & - & - & - & 2 & - & - & 18 & - & - & - & - & - & 20 & - & - \\
\hline $\begin{array}{l}\text { Sobral } \\
\text { Tabuleiro do }\end{array}$ & - & - & - & 1 & - & - & 212 & 26 & 12,3 & 94 & 19 & 20,2 & 2 & - & - & 309 & 45 & 14,6 \\
\hline Norte & - & - & - & - & - & - & 279 & 10 & 3,4 & 11 & - & - & - & - & - & 290 & 10 & 3,4 \\
\hline Tamboril & 3 & - & - & - & - & - & 99 & 6 & 6,1 & 1 & - & - & - & - & - & 103 & 6 & 5,8 \\
\hline Tauá & - & - & - & 1 & - & - & 53 & 3 & 5,2 & - & - & - & - & - & - & 54 & 3 & 5,6 \\
\hline Umari & - & - & - & - & - & - & 22 & 1 & 4,5 & 26 & 2 & 7.7 & - & - & - & 48 & 3 & 6,4 \\
\hline Uruburetama & - & - & - & - & - & - & 57 & 23 & 40,4 & - & - & - & - & - & - & 57 & 23 & 40,4 \\
\hline Várzea Alegre & 18 & - & - & - & - & - & 90 & - & - & 4 & 1 & $\cdots$ & - & - & - & 112 & 1 & 1.1 \\
\hline Total & 5.071 & 197 & 3,9 & 28 & 5 & 17,9 & 23.447 & 1.931 & 8,2 & 5.359 & 227 & 4,2 & 491 & 5 & 1,0 & 34.396 & 2.365 & 6,9 \\
\hline $\begin{array}{l}\text { Total de } \\
\text { Municipios com } \\
\text { Triatomíneos }\end{array}$ & 58 & & & 17 & & & 85 & & & 74 & & & 23 & & & 104 & & \\
\hline
\end{tabular}


TABELA 10

Triatomineos Examinados no Laboratório da SUCAM - Ceará, no Perlodo 1964 - 1974 (")

\begin{tabular}{|c|c|c|c|c|c|c|c|c|c|c|c|c|c|c|c|c|c|c|}
\hline \multirow{2}{*}{ Micro-Regibes } & \multicolumn{3}{|c|}{ P. megistus } & \multicolumn{3}{|c|}{ P. Iutzi } & \multicolumn{3}{|c|}{ T. brasiliensis } & \multicolumn{3}{|c|}{ T. pseudomaculata } & \multicolumn{3}{|c|}{ R. nasutus } & \multicolumn{3}{|c|}{ Total } \\
\hline & Exam. & Pos. & \% & Exam. & Pos. & $\%$ & Exam. & Pos. & $\%$ & Exam. & Pos. & $\%$ & Exam. & Pos. & $x$ & Exam. & Pos. & \% \\
\hline \multicolumn{19}{|l|}{ Lnoral do } \\
\hline $\begin{array}{l}\text { Acaraú } \\
\text { Bajxo Modio }\end{array}$ & - & - & - & - & - & - & - & - & - & 1 & 1 & $\ldots$ & - & - & - & 1 & 1 & $\cdots$ \\
\hline Acará & 1 & - & - & 2 & - & - & 20 & - & - & 5 & - & - & - & - & - & 28 & - & - \\
\hline Uruburetame & 3 & - & - & 1 & - & - & 507 & 26 & 5,1 & 634 & 2 & 0,3 & 230 & - & - & 1.375 & 28 & 2,0 \\
\hline $\begin{array}{l}\text { Fortaleza } \\
\text { Litoral de }\end{array}$ & 8 & - & - & 4 & 2 & $\ldots$ & 33 & 1 & 3,0 & 1 & - & - & 24 & 2 & 8,3 & 70 & 5 & 7,1 \\
\hline Pacajús & 4 & - & - & - & - & - & 81 & 2 & 2,5 & 4 & - & - & 1 & - & - & 90 & 2 & 2,2 \\
\hline Baxo Jaguaribe & 120 & 13 & - & 7 & 1 & $\ldots$ & 11.775 & 1.123 & 9,5 & 2.228 & 119 & 5,3 & i96 & 3 & 1,5 & 14.326 & 1.259 & 8,8 \\
\hline Ibiapebe & 1 & - & - & - & - & - & - & - & - & 1 & - & - & - & - & - & 2 & - & - \\
\hline $\begin{array}{l}\text { Sotral } \\
\text { Sertoes de }\end{array}$ & 262 & - & - & 3 & 1 & $\ldots$ & 1.339 & 53 & 4,0 & 267 & 19 & 7,1 & 5 & - & - & 1.876 & 73 & 3,9 \\
\hline Caninds & - & - & - & - & - & - & 224 & 12 & 5,4 & 19 & - & - & - & - & - & 243 & 12 & 4,9 \\
\hline Baturité & 245 & 14 & 5,7 & 1 & - & - & 34 & 2 & 5,9 & 7 & - & - & - & - & - & 287 & 16 & 5,6 \\
\hline $\begin{array}{l}\text { Meridional } \\
\text { Sertios de }\end{array}$ & 13 & 2 & $\cdots$ & 1 & - & - & 1.424 & 47 & 3,3 & 14 & - & - & 1 & - & - & 1.453 & 49 & 3,4 \\
\hline $\begin{array}{l}\text { Crateús } \\
\text { Sortóes }\end{array}$ & 6 & - & - & 7 & 1 & $\ldots$ & 1.184 & 80 & 6,8 & 236 & 9 & 3,8 & 12 & - & - & 1.445 & 90 & 6,2 \\
\hline $\begin{array}{l}\text { Quixeramobim } \\
\text { Sortzes } \mathrm{S} \text {. }\end{array}$ & 1 & - & - & - & - & - & 63 & - & - & 2 & - & - & - & - & - & 66 & - & - \\
\hline Pompeu & - & - & - & - & - & - & 1 & - & - & - & - & - & - & - & - & 1 & - & - \\
\hline Modio Jaguaribe & 11 & - & - & - & - & - & 267 & 5 & 1.9 & 170 & 3 & 1,8 & 2 & - & - & 450 & 8 & 1,8 \\
\hline $\begin{array}{l}\text { Serra do Pereiro } \\
\text { Sertlo dos }\end{array}$ & 24 & - & - & - & - & - & 57 & - & - & 340 & 7 & 2,1 & - & - & - & 421 & 7 & 1,7 \\
\hline Inhamuns & 29 & 1 & - & 1 & - & - & 473 & 28 & 5.9 & 31 & - & - & - & - & - & 534 & 29 & 5,4 \\
\hline $\begin{array}{l}\text { Iguatú } \\
\text { Sorťo do }\end{array}$ & 30 & - & - & - & - & - & 672 & 27 & 4,0 & 210 & 7 & 3,3 & - & - & - & 912 & 34 & 3,7 \\
\hline $\begin{array}{l}\text { Salgado } \\
\text { Serrana do }\end{array}$ & 17 & 1 & $\cdots$ & - & - & - & 4.551 & 502 & 11,0 & 780 & 42 & 5,4 & 12 & - & - & 5.360 & 545 & 10,2 \\
\hline Caririaçu & 189 & 2 & 1.1 & - & - & - & 291 & 3 & 1,0 & 35 & 2 & 5,7 & - & - & - & 515 & 7 & 1,4 \\
\hline $\begin{array}{l}\text { Sertto do Cariri } \\
\text { Cheppede do }\end{array}$ & 113 & 3 & 2,7 & - & - & - & 323 & 18 & 5,6 & 143 & 3 & 2,1 & - & - & - & 579 & 24 & 4,1 \\
\hline $\begin{array}{l}\text { Araripe } \\
\text { Cariri }\end{array}$ & $\begin{array}{r}74 \\
3.920\end{array}$ & $\begin{array}{r}2 \\
159\end{array}$ & $\begin{array}{l}2,7 \\
4,1\end{array}$ & $\begin{array}{r}1 \\
-\end{array}$ & $\overline{-}$ & $\begin{array}{l}- \\
-\end{array}$ & $\begin{array}{r}23 \\
105\end{array}$ & - & $\overline{1,9}$ & $\begin{array}{r}49 \\
182\end{array}$ & $\begin{array}{r}1 \\
12\end{array}$ & $\begin{array}{l}2,0 \\
6,6\end{array}$ & - & $\begin{array}{l}- \\
-\end{array}$ & $\overline{-}$ & $\begin{array}{r}147 \\
4.215\end{array}$ & $\begin{array}{r}3 \\
173\end{array}$ & $\begin{array}{l}2,0 \\
4,1\end{array}$ \\
\hline Total & 5.071 & 197 & 3,9 & 28 & 5 & 17,9 & 23.447 & 1.931 & 8,2 & 5.359 & 227 & 4,2 & 491 & 5 & 1,0 & 34.396 & 2.365 & 6,9 \\
\hline
\end{tabular}

(*) Até o més de novembro 
TABELA 10

Triatomíneos Examinados no Laboratório da SUCAM - Coará, no Perlodo 1964 - 1974 (")

\begin{tabular}{|c|c|c|c|c|c|c|c|c|c|c|c|c|c|c|c|c|c|c|}
\hline \multirow{2}{*}{ Micro-Regibes } & \multicolumn{3}{|c|}{ P. megistus } & \multicolumn{3}{|c|}{ P. Iutzi } & \multicolumn{3}{|c|}{ T. brasiliensis } & \multicolumn{3}{|c|}{ T. pseudomaculata } & \multicolumn{3}{|c|}{ A. nasutus } & \multicolumn{3}{|c|}{ Total } \\
\hline & Exam. & Pos. & $\%$ & Exam. & Pos. & $\%$ & Exam. & Pos. & $\%$ & Exam. & Pos. & $\%$ & Exam. & Pos. & $\%$ & Exam. & Pos. & $\%$ \\
\hline \multicolumn{19}{|l|}{$\begin{array}{l}\text { Litoral do } \\
\text { Cemocim e }\end{array}$} \\
\hline $\begin{array}{l}\text { Acaraú } \\
\text { Buxo Mbdio }\end{array}$ & - & - & - & - & - & - & - & - & - & 1 & 1 & $\cdots$ & - & - & - & 1 & 1 & $\cdots$ \\
\hline Acorál & 1 & - & - & 2 & - & - & 20 & - & - & 5 & - & - & - & - & - & 28 & - & - \\
\hline Uruburetema & 3 & - & - & 1 & $\overline{0}$ & - & 507 & 26 & 5,1 & 634 & 2 & 0,3 & 230 & - & - & 1.375 & 28 & 2.0 \\
\hline $\begin{array}{l}\text { Forteleze } \\
\text { Litoral do }\end{array}$ & 8 & - & - & 4 & 2 & $\ldots$ & 33 & 1 & 3,0 & 1 & - & - & 24 & 2 & 8,3 & 70 & 5 & 7,1 \\
\hline Pacajús & 4 & - & - & - & - & - & 81 & 2 & 2,5 & 4 & - & - & 1 & - & - & 90 & 2 & 2,2 \\
\hline Baixo Jaguaribe & 120 & 13 & - & 7 & 1 & $\ldots$ & 11.775 & 1.123 & 9,5 & 2.228 & 119 & 5,3 & i96 & 3 & 1,5 & 14.326 & 1.259 & 8,8 \\
\hline Ibiapabe & 1 & - & - & - & - & - & - & - & - & 1 & - & - & - & - & - & 2 & - & - \\
\hline $\begin{array}{l}\text { Sotral } \\
\text { Sertoes de }\end{array}$ & 262 & - & - & 3 & 1 & $\cdots$ & 1.339 & 53 & 4,0 & 267 & 19 & 7,1 & 5 & - & - & 1.876 & 73 & 3,9 \\
\hline $\begin{array}{l}\text { Canindt } \\
\text { Sorra de }\end{array}$ & - & - & - & - & - & - & 224 & 12 & 5,4 & 19 & - & - & - & - & - & 243 & 12 & 4,9 \\
\hline $\begin{array}{l}\text { Baturité } \\
\text { Ibiapaba }\end{array}$ & 245 & 14 & 5,7 & 1 & - & - & 34 & 2 & 5,9 & 7 & - & - & - & - & - & 287 & 16 & 5,6 \\
\hline $\begin{array}{l}\text { Moridional } \\
\text { Sortoes do }\end{array}$ & 13 & 2 & $\ldots$ & 1 & - & - & 1.424 & 47 & 3,3 & 14 & - & - & 1 & $\tau$ & - & 1.453 & 49 & 3,4 \\
\hline $\begin{array}{l}\text { Crateús } \\
\text { Sertbes }\end{array}$ & 6 & - & - & 7 & 1 & $\cdots$ & 1.184 & 80 & 6,8 & 236 & 9 & 3,8 & 12 & - & - & 1.445 & 90 & 6,2 \\
\hline $\begin{array}{l}\text { Quixeramobim } \\
\text { Sortoes S. }\end{array}$ & 1 & - & - & - & - & - & 63 & - & - & 2 & - & - & - & - & - & 66 & - & - \\
\hline Pompou & - & - & - & - & - & - & 1 & - & - & - & - & - & - & - & - & 1 & - & - \\
\hline Mrdio Jaguaribe & 11 & - & - & - & - & - & 267 & 5 & 1,9 & 170 & 3 & 1,8 & 2 & - & - & 450 & 8 & 1,8 \\
\hline $\begin{array}{l}\text { Sorra do Pereiro } \\
\text { Sertito dos }\end{array}$ & 24 & - & - & - & - & - & 57 & - & - & 340 & 7 & 2,1 & - & - & - & 421 & 7 & 1,7 \\
\hline Inhemuns & 29 & 1 & - & 1 & - & - & 473 & 28 & 5,9 & 31 & - & - & - & - & - & 534 & 29 & 5,4 \\
\hline $\begin{array}{l}\text { Iguatí } \\
\text { Sertso do }\end{array}$ & 30 & - & - & - & - & - & 672 & 27 & 4,0 & 210 & 7 & 3,3 & - & - & - & 912 & 34 & 3,7 \\
\hline $\begin{array}{l}\text { Selgacto } \\
\text { Serrana do }\end{array}$ & 17 & 1 & $\ldots$ & - & - & - & 4.551 & 502 & 11,0 & 780 & 42 & 5,4 & 12 & - & - & 5.360 & 545 & 10,2 \\
\hline Caririacu & 189 & 2 & 1.1 & - & - & - & 291 & 3 & 1,0 & 35 & 2 & 5,7 & - & - & - & 515 & 7 & 1,4 \\
\hline $\begin{array}{l}\text { Serttio do Cariri } \\
\text { Chapade do }\end{array}$ & 113 & 3 & 2,7 & - & - & - & 323 & 18 & 5,6 & 143 & 3 & 2,1 & - & - & - & 579 & 24 & 4,1 \\
\hline $\begin{array}{l}\text { Araripe } \\
\text { Cariri }\end{array}$ & $\begin{array}{r}74 \\
3.920\end{array}$ & $\begin{array}{r}2 \\
159\end{array}$ & $\begin{array}{l}2,7 \\
4,1\end{array}$ & $\begin{array}{l}1 \\
-\end{array}$ & $\begin{array}{l}- \\
-\end{array}$ & $\begin{array}{l}- \\
-\end{array}$ & $\begin{array}{r}23 \\
105\end{array}$ & - & $\overline{1,9}$ & $\begin{array}{r}49 \\
182\end{array}$ & $\begin{array}{r}1 \\
12\end{array}$ & $\begin{array}{l}2,0 \\
6,6\end{array}$ & - & $\overline{-}$ & - & $\begin{array}{r}147 \\
4.215\end{array}$ & $\begin{array}{r}3 \\
173\end{array}$ & $\begin{array}{l}2,0 \\
4,1\end{array}$ \\
\hline Total & 5.071 & 197 & 3,9 & 28 & 5 & 17,9 & 23.447 & 1.931 & 8,2 & 5.359 & 227 & 4,2 & 491 & 5 & 1,0 & 34.396 & 2.365 & 6,9 \\
\hline
\end{tabular}


TABELA 11

Triatomineos Examinados no Laboratório da SUCAM - Ceará, no Período 1964 - 1974 (")

\begin{tabular}{|c|c|c|c|c|c|c|c|c|c|c|c|c|c|c|c|c|c|c|c|}
\hline \multirow{2}{*}{ Ano } & \multirow{2}{*}{$\begin{array}{l}\text { No de loca- } \\
\text { lidades tra- } \\
\text { Ihadas }\end{array}$} & \multicolumn{3}{|c|}{ P. megistus } & \multicolumn{3}{|c|}{ P. lutzi } & \multicolumn{3}{|c|}{ T. brasiliensis } & \multicolumn{3}{|c|}{ T. pseudomaculata } & \multicolumn{3}{|c|}{ R. nasutus } & \multicolumn{3}{|c|}{ Total } \\
\hline & & Exam. & Pos. & $\%$ & Exam. & Pos. & \% & Exam. & Pos. & $\%$ & Exam. & Pos. & $\%$ & Exam. & Pos. & $\%$ & Exam. & Pos. & $\%$ \\
\hline 1964 & 268 & 308 & 15 & 4,9 & 6 & 3 & $\ldots$ & 3.037 & 262 & 8,6 & 313 & 3 & 1,0 & 261 & - & - & 3.925 & 283 & 7,2 \\
\hline 1965 & 239 & 1.742 & 97 & 5,6 & 7 & 1 & $\ldots$ & 1.101 & 45 & 4,1 & 329 & 7 & 2,1 & 13 & - & - & 3.192 & 150 & 4,7 \\
\hline 1966 & 400 & 403 & 13 & 3,2 & 1 & - & - & 3.945 & 183 & 4,6 & 432 & 10 & 2,3 & 4 & 1 & $\ldots$ & 4.785 & 207 & 4,3 \\
\hline 1967 & 66 & 316 & - & - & 1 & 1 & $\ldots$ & 245 & 11 & 4,5 & 17 & 2 & $\ldots$ & 1 & 1 & $\ldots$ & 580 & 15 & 2,6 \\
\hline 1968 & 105 & 10 & - & - & - & - & - & 763 & 61 & 8,0 & 216 & 5 & 2,3 & 3 & - & - & 992 & 66 & 6,7 \\
\hline 1969 & 121 & 165 & 4 & 2,4 & 1 & - & - & 521 & 11 & 2,1 & 326 & 1 & 0,3 & 1 & - & - & 1.014 & 16 & 1,6 \\
\hline 1970 & 263 & 229 & 15 & 6,6 & - & - & - & 1.128 & 67 & 5,9 & 755 & 22 & 2,9 & 8 & - & - & 2.120 & 104 & 4,9 \\
\hline 1971 & 86 & 275 & 11 & 4,0 & 2 & - & - & 678 & 54 & 8,0 & 147 & 9 & 6,1 & 3 & - & - & 1.105 & 74 & 6,7 \\
\hline 1972 & 830 & 790 & 10 & 2,5 & 3 & - & - & 720 & 76 & 10,6 & 401 & 18 & 4,5 & 34 & 2 & 5,9 & 1.948 & 116 & 6,0 \\
\hline 1973 & 864 & 822 & 19 & 2,3 & 7 & - & - & 10.414 & 1.054 & 10,1 & 1.833 & 96 & 5,2 & 161 & 1 & 0,6 & 13.237 & 1.170 & 8,8 \\
\hline 1974 & 179 & 11 & 3 & $\ldots$ & - & - & - & 895 & 107 & 12,0 & 590 & 54 & 9,2 & 2 & - & - & 1.498 & 164 & 10,9 \\
\hline Total & 3.421 & 5.071 & 197 & 3,9 & 28 & 5 & 17,9 & 23.447 & 1.931 & 8,2 & 5.359 & 227 & 4,2 & 491 & 5 & 1,0 & 34.396 & 2.365 & 6,9 \\
\hline
\end{tabular}

(") Até o més de novembro. 
Jaguaribe (Alencar et cols. 1965): 15,4\%. A Tabela 10 mostra uma taxa global de $8,2 \%$, com cifras acima da média no Baixo Jaguaribe e no Sertão do Salgado.

Esta espécie é a principal transmissora da Doença de Chagas no Estado do Ceará, mas em algumas regiões outras espécies apresentam taxas de infecção mais elevada, como veremos adiante. É encontrado em $91,3 \%$ das micro-regiões.

É um triatomíneo semi-doméstico, colonizando facilmente em ecótopos fora e próximos das habitações ${ }^{21}$ e infectado em $69,6 \%$ delas.

As variações anuais mostram extremos para baixo (ano de 1969: $2,1 \%$ ) e para cima (10,6 10,1 e 12,00) nos três últimos anos da série.

b) Triatoma pseudomaculata (Mapa 2). É a segunda espécie do Estado, e apresentou uma taxa global de infecção de $4,2 \%$. (Tabela 10): Apresenta uma freqüência elevada no Baixo Jaguaribe e no Sertão do Salgado. Mas as taxas de infecção mais elevadas foram observadas em Sobral, Cariri e Serrana de Caririaçu. Encontrado em $95,7 \%$ das micro-regiões, aparece infectado em $56,5 \%$ delas. As variações anuais das taxas de infecção mostram os anos de 1967, 1974 e 1971 como os de maiores índices. A espécie é entretanto pouco doméstica, colonizando melhor fora das habitações.

c) Panstrongy/us megistus (Mapa 1). É a terceira espécie em importância epidemiológica no Estado, porém é a de maior importância no Cariri, especialmente nos municípios de BarbaIha e Crato. É uma espécie mais doméstica que as demais, porém é observada também em ecótopos fora das casas, como sejam abrigos de animais. Ela aparece mais prevalente que as demais nas regiões serranas, mas é encontrado em quase todas $(87,0 \%)$.

A taxa global de infecção é menor que as duas espécies anteriores, mas as taxas por região mostram-se maiores que as demais espécies nos seguintes municípios: Barbalha, Jardim, Jati, Limoeiro do Norte, Potengi e Redenção. É encontrado positivo em $39,1 \%$ das micro-regiões. As variações anuais mostram que em 1967 e 1968 não se observou infecção por tripanosomas e os maiores indices corresponderam aos anos de 1970, 1965, 1964 e 1971 (Tabela 11). d) Rhodnius nasutus (Mapa 2). É espécie de pouca densidade no Estado, encontrada especialmente nos municípios de Itapajé e Morada Nova. É encontrada em mais 21 municípios do Estado, além dos dois citados 10 micro-regiões), sendo capturados poucos exemplares (1 a 17). Não parece ter importância na transmissão da Doença de Chagas, mas é encontrado infectado em duas micro-regiões $(8,7 \%)$.

e) Panstrongylus lutzi (Mapa 2). É uma espécie encontrada dentro das habitações em poucos municípios e raramente $(10$ micro-regiões, sendo encontrado infectado em 4). 0 número de exemplares, sempre de adultos, variou de 1 a 3 e em uma oportunidade 6 exemplares. Visto que é encontrado quase sempre nas salas e somente adultos, tem-se como certo que coloniza fora das habitações em ecótopos de animais. Apesar de que sua taxa de infecção é elevada (17,9\%) não pode ser considerado transmissor da Doença de Chagas no Ceará.

Provavelmente entra na casa atraído pela luz, pois as referências dos habitantes das regiões em que é encontrado afirmam isso. É mais encontrado nos sertões de Crateús e no Baixo Jaguaribe (Tabela 10). Os anos de maior freqüência da série são os seguintes: 1965, 1973 e 1964 (Tabela 11).

\section{CONCLUSÕES}

A estrutura espacial do Ceará compõe-se de sertões, serras, brejos, vales e litoral.

De 1921 a 1974 foram capturados dentro das habitações no Ceará 5 espécies de triatomineos, as quais foram também capturadas em ecótopos de animais domésticos e silvestres.

As microregiões em que há maior prevalência e maiores taxas de infecção das espécies transmissoras de Doença de Chagas são: Baixo Jaguaribe, Sertões do Salgado, Cariri, Serra de Baturité, Sobral, Serrana de Caririaçu, Uruburetama, Sertão dos Inhamuns.

Das 6 (seis) espécies de triatomíneos transmissores da Doença de Chagas no Brasil, 3 existem no Ceará, condicionando uma intensa transmissão de $T$. cruzi entre os animais domés- 
ticos e silvestres: $T$. brasiliensis, $T$. pseudomaculata e $P$. megistus. Considera-se ademais a possibilidade de transmissão muito esporádica pelo $R$. nasutus e pelo $P$. lutzi.

As taxas de infecção por $T$. cruzi são moderadas habitualmente; em poucas ocasiões essas taxas se apresentam elevadas, especialmente nos Municípios de: Baturité, Baixio, Barba-
Iha, Crato, Limoeiro do Norte, Hidrolândia, Icó, Independência, Palhano, Parambu, Quixeré, Russas, Sobral e Uruburetama. Ai as taxas variaram de $8,6 \%$ a $40,4 \%$.

Não são disponíveis informações sobre as diferenças ecológicas de espécies e os hábitos alimentares das diferentes espécies transmissoras da Doença de Chagas no Ceará.

\section{SUMMARY}

The paper shows some geographical informations about the State of Ceara, Brasil, that is divided in 23 micro-regions and 141 counties. In 129 of these counties were collected triatomines (91,5\%), according all the informations published from 1957 to 1974. The main species is the Triatoma brasiliensis, semi-domestic, 1,0 to $40,4 \%$ of them infected. The second species is the Triatoma pseudomaculata $168,8 \%$ of the counties); the infection rates are between 0,3 and $7,1 \%$. The third species is the Panstrongylus megistus $(61,7 \%$ of the counties) with rates of intection between $3,9 \%$ and $25,9 \%$. The fourth species is the Rhodnius nasutus $117,7 \%$ of the counties) infected $1,0 \%$. The last species, Panstrongylus lutzi, a sy/vatic, is seen inside houses in $18,4 \%$ of the counties, but only adult forms and showing high rates of intection $(17,9 \%)$. The most infected micro-regions of the State are: "sertão" of Senador Pompeu, "sertão" of Inhamuns and "baixo" Jaguaribe.

\section{REFERÊNCIAS BIBLIOGRÁFICAS}

1. ALBUQUERQUE, A.F.R., BRITO, S. \&! MORAES, M.O. - Importante foco de mal de Chagas e Leishmaniose Visceral Americana no Vale do Cariri (Estados do Ceará e Pernambuco). Hospital (Rio de Janeiro). $21: 61-69,1942$.

2. ALENCAR, J.E., ALMEIDA, J.O., SHERLOCK, V., FRANÇA, A.P. \& LEITE, L. Estudos sobre a epidemiologia da Doença de Chagas no Ceará. II Novos dados. Rev. Bras. Malariol. D. Trop. 15:551-565, 1963.

3. ALENCAR, J.E. - Estudos sobre a epidemiologia da Doença de Chagas no Ceará. III Região do Baixo Jaguaribe. Rev. Bras. Malariol. D. Trop. 17:149-158, 1965.

4. ALENCAR, J.E. \& SHERLOCK, V.A. Triatomíneos capturados em domicílios no Estado do Ceará - Brasil. Bol Soc. Cear. Agron., 3:49-54, 1962.

5. BUSTAMANTE, F.M. - Distribuição geográfica dos transmissores da doença de Chagas no Brasil e sua relação com certos fatores climáticos. Epidemiologia e profilaxia da enfermidade. Rev. Bras. Malariol. $D$. Trop. 9:191-211, 1957.
6. CORRÊA, R.R. - Informe sobre a Doença de Chagas no Brasil e em especial no Estado de São Paulo - Rev. Bras. Malariol. D. Trop., 20:39-81, 1968.

7. DEANE, L.M. \& DEANE, M.P. - Notas sobre transmissores e reservatórios do Trypanosoma cruzi no Noroeste do Estado do Ceará. Rev. Bras. Malariol. D. Trop. 9:577-595, 1957.

8. FUNDAÇÃO, I.B.G.E. - Sinópse preliminar do censo demográfico. VIII Recenseamento Geral, 1970.

9. GONZAGA, A. - Climatologia e Nosologia do Ceará, 1925. Rio de Janeiro, 171 pp. Ed. Baptista de Sousa.

10. MACHADO, H. - Identificação de triatomíneo infectado com tripanosomas capturados no Município de Redenção - Ceará. Sessão Centro M. Cear. 24 Janeiro, 1951.

11. MACHADO, H. \& PINTO, O.S. - Contribuição ao conhecimento da distribuição geográfica dos triatomíneos domiciliários e de seus índices de infecção natural no Estado do Ceará, Brasil. Rev. Bras. Malariol. D. Trop., 4:157-170, 1952. 
12. JUCÁ, A. \& CUNHA, R.V. - Contribuição ao estudo da Doença de Chagas no Ceará. Ceará Médico, 29:36-38, 1950.

13. SALES, J.B. - Geografia Médica do Estado do Ceará. Distribuição geográfica da Doen- ça de Chagas. Rev. Bras. Med., 19:788-789, 1952.

14. SUCAM - Ministério da Saúde - Dados sobre captura de triatomíneos no Estado do Ceará. Papéis datilografados (1966). 